\title{
Volatile Changes in Cantaloupe during Growth, Maturation, and in Stored Fresh-cuts Prepared from Fruit Harvested at Various Maturities
}

\author{
John C. Beaulieu \\ Southern Regional Research Center, Agricultural Research Service, U.S. Department of Agriculture, \\ New Orleans, LA 70124
}

\begin{abstract}
Additional INDEX words. aroma, Cucumis melo, flavor, gas chromatography, mass spectrometry, maturity, melon, minimal processing, solid phase microextraction

ABSTRACT. A likely reason why consumers are not repeat buyers of many fresh-cut fruit is inconsistent or unsatisfactory flavor and/or textural quality. Research toward understanding mechanisms responsible for generation, and/or loss of flavor compounds in fresh-cut fruit is limited. Solid phase microextraction (SPME) and gas chromatography-mass spectrometry (GC-MS) were utilized to study flavor volatile profiles in anthesis-tagged cantaloupe (Cucumis melo L. var. reticulatus Naud. cv. Sol Real) during growth, development, and for fresh-cuts prepared from fruit with five distinctly different harvest maturities. One-quarter-slip fruit had a clearly green, well-attached peduncle; $1 / 2$-slip fruit had a distinct abscission detectable at the peduncle, 3/4-slip fruit were approaching commercial harvest, full-slip (FS) fruit are or will cleanly separate from the vine with light pressure; and over-ripeness (OR) was precisely categorized as 2 days past FS. Recovery of total volatiles displayed a linear response and most volatile classes (except aldehydes) generally followed a trend upon processing where FS > 3/4-slip > 1/2-slip > 1/4-slip. On day 0, only 70.0\%, 37.7\%, and $20.5 \%$ total volatiles were recovered in 3/4-slip, 1/2-slip, and 1/4-slip fruit, compared to FS fruit. During fresh-cut storage, percent total esters followed an increasing linear trend that was maturity-dependent. Percent total aromatics and percent aldehydes followed a linear trend that was maturity-dependent whereby 1/4-slip > 1/2-slip > 3/4-slip > FS. During storage, the relative percentage of acetates decreased, and displayed a maturity-dependent curvilinear trend. The magnitude of the slope decreased with maturity, indicating that the effect of storage time decreased as maturity increased. In FS, 3/4-slip, 1/2-slip, and 1/4-slip cubes, acetates comprised $66.9 \%$ of all compounds recovered on day 0 yet, only $26.1 \%$ to $44.2 \%$, and $21.3 \%$ to $32.6 \%$ remained on days 9 and 14, respectively. For all maturities, a curvilinear increase in relative percentage of nonacetate esters was observed during storage. There was a uniform change in the ester balance (nonacetate ester:acetate ratio) during fresh-cut storage, which was independent of initial processing maturity. The overall ester ratio changed roughly 2 -fold after just 2 days in optimum storage, and after 5 days it increased more than 3-fold. The shift in endogenous ester compounds could be partially responsible for the apparent loss of characteristic flavor in fresh-cut cantaloupe through long-term storage.
\end{abstract}

The most recent comprehensive review of volatile compounds in melons tabulated 219 compounds (Nijssen et al., 1996). Yet, my recent survey of the literature indicates that more than 250 volatile compounds have been reported. Most typical sample preparations for compound isolation involve steps that are time and labor intensive, prone to volatile loss, and often use solvents that are toxic or potential carcinogens. Furthermore, solvent extractions are generally accomplished at high temperatures or under reduced pressure. These conditions can destroy or alter some volatile flavor compounds and/or produce oxidative products (Gardner, 1989). Subsequently, flavor and off-flavor aromas have recently been assessed in numerous fruit and juices by SPME (Beaulieu and Grimm, 2001; Ibáñez et al., 1998; Jia et al., 1998) because it is rapid, relatively inexpensive and does not require solvents, purge and trap, concentration, or vigorous extraction and heating, which

Received for publication 17 Dec. 2003. Accepted for publication 22 June 2005 The author thanks Dean Liere and Alex May of Syngenta Seeds, Inc.; ROGERS Brand Vegetable Seeds, for managing, tagging, and supplying anthesis-tagged immature and mature cantaloupe fruit; Jeanne M. Lea for volatile data analysis; and Amber D. Harts and James A. Miller for laboratory assistance. Statistical advice and support were obtained from Vicki Lancaster, Neptune and Company, Inc. The mention of firm names or trade products does not imply that they are endorsed or recommended by the U.S. Dept. of Agriculture over other similar firms or products not mentioned.

${ }^{1}$ Research Plant Physiologist; to whom correspondence should be addressed, (beaulieu@srrc.ars.usda.gov); Tel. 504.286.4471; Fax. 504.286.4419 may alter endogenous compounds. Eighty-six compounds, and an additional 53 not previously reported in the literature, were routinely recovered from cantaloupe using automated headspace SPME (Beaulieu and Grimm, 2001).

There are 19 compounds that have been considered characteristic impact flavor or aroma compounds (CIFAC) in ripe $C$. melo (Buttery et al., 1982; Horvat and Senter, 1987; Kemp et al., 1972; Nussbaumer and Hostettler, 1996; Schieberle et al., 1990; Wyllie et al., 1994, 1995). In addition, five sulfur compounds (Scompounds) were presumed to be flavor important in numerous C. melo cultivars (Horvat and Senter, 1987; Wyllie et al., 1994; Wyllie and Leach, 1992) (Table 1).

Cutting or wounding tissue increases respiration rates, woundinduced ethylene production, and causes major tissue disruption as sequestered enzymes and substrates become mixed (Toivonen and DeEll, 2002; Watada and Qi, 1999; Wiley, 1994). Freshcut processing also increases the surface area per unit volume, which accelerates water loss. Altered water activity and mixing of intracellular and intercellular enzymes with substrates may also contribute to flavor and texture changes/loss during or after cutting, which shortens storage life. Consistent flavor and postharvest quality of fresh-cut fruit is required for sustained consumer acceptance. Aside from cost, a likely reason why consumers are not repeat buyers of many fresh-cut fruit is unsatisfactory flavor and/or textural quality (Beaulieu, 2001). This remains a challenging area for the fresh-cut fruit industry. 
Table 1. Integrated and analyzed volatile compounds recovered by solid phase microextraction, gas chromatograph-mass spectrometry in developing and mature cantaloupe, and characteristic impact flavor and aroma compounds [CIFACs (in italics)] reported in the Cucumis melo literature. ${ }^{\mathrm{z}}$

\begin{tabular}{|c|c|c|c|c|c|c|}
\hline $\begin{array}{l}\text { Compound class } \\
\text { Compound }\end{array}$ & $\begin{array}{l}\mathrm{RT}^{\mathrm{y}} \\
(\mathrm{min})\end{array}$ & $\begin{array}{c}\mathrm{RI}^{\mathrm{x}} \\
(\mathrm{DB}-5)^{\mathrm{u}}\end{array}$ & $\begin{array}{l}\text { T-ion }{ }^{\mathrm{w}} \\
(\mathrm{m} / \mathrm{z})^{\mathrm{t}}\end{array}$ & $\begin{array}{l}\text { Q-ion }{ }^{\mathrm{v}} \\
(\mathrm{m} / \mathrm{z})\end{array}$ & CAS no. ${ }^{s}$ & $\mathrm{ID}^{\mathrm{r}}$ \\
\hline \multicolumn{7}{|l|}{ Esters (nonacetate) } \\
\hline methyl 2-methylpropanoate & 2.11 & 690 & 71 & 87 & $547-63-7$ & RI, MS \\
\hline ethyl propanoate & 2.31 & 708 & 57 & 75 & $105-37-3$ & RI, MS \\
\hline ethyl 2-methylpropanoate & 2.81 & 751 & 71 & 116 & $97-62-1$ & RI, MS \\
\hline methyl 2-methylbutanoate & 3.03 & 772 & 88 & 57 & $868-57-5$ & RI, MS \\
\hline ethyl butanoate & 3.37 & 803 & 71 & 88 & $105-54-4$ & RI, MS \\
\hline ethyl 2-methylbutanoate & 4.21 & 846 & 102 & 85 & $7452-79-1$ & RI, MS \\
\hline ethyl pentanoate & 5.27 & 900 & 88 & 85 & $539-82-2$ & RI, MS \\
\hline methyl hexanoate & 5.82 & 922 & 74 & 87 & $106-70-7$ & RI, MS \\
\hline butyl butanoate & 7.67 & 994 & 71 & 89 & $109-21-7$ & RI, MS \\
\hline ethyl hexanoate & 7.76 & 999 & 88 & 99 & $123-66-0$ & RI, MS \\
\hline methyl heptanoate & 8.42 & 1021 & 113 & 101 & $106-73-0$ & MS \\
\hline 2-methyl butylbutanoate & 9.40 & 1056 & 71 & 70 & $51115-64-1$ & RI, MS \\
\hline ethyl $(E)$-4-heptenoate & 10.35 & 1090 & 67 & 88 & $54340-70-4$ & MS \\
\hline propyl hexanoate & 10.42 & 1094 & 99 & 117 & $626-77-7$ & RI, MS \\
\hline ethyl heptanoate & 10.50 & 1099 & 88 & 113 & $106-30-9$ & RI, MS \\
\hline 3-methylbutyl hexanoate & 14.12 & 1254 & 99 & 70 & 2198-61-0 & RI, MS \\
\hline pentyl hexanoate & 14.70 & 1282 & 99 & 117 & $540-07-8$ & RI, MS \\
\hline \multicolumn{7}{|l|}{ Acetates } \\
\hline 2-methylpropyl acetate & 2.99 & 768 & 43 & 56 & $110-19-0$ & RI, MS \\
\hline butyl acetate & 3.59 & 812 & 43 & 56 & $123-86-4$ & RI, MS \\
\hline 3-methylbutyl acetate & 4.79 & 876 & 87 & 70 & $123-92-2$ & MS \\
\hline 2-methylbutyl acetate & 4.88 & 877 & 70 & 73 & $624-41-9$ & MS \\
\hline unknown alkyl acetate & 7.19 & 975 & 56 & 84 & & \\
\hline (Z)-3-hexenyl acetate & 7.96 & 1004 & 43 & 67 & $3681-71-8$ & RI, MS \\
\hline hexyl acetate & 8.19 & 1011 & 56 & 84 & $142-92-7$ & RI, MS \\
\hline (E)-3-hexenyl acetate & 8.32 & 1018 & 67 & 82 & $33467-73-1$ & MS \\
\hline (Z) 6-nonenyl acetate & $\mathrm{NR}^{\mathrm{q}}$ & & & & & \\
\hline (Z, Z) 3,6-nonadienyl acetate & NR & & & & & \\
\hline benzyl acetate & 12.25 & 1164 & 108 & 91 & $140-11-4$ & RI, MS \\
\hline phenylethyl acetate & 13.93 & 1243 & 91 & 164 & $101-97-3$ & RI, MS \\
\hline ethyl phenylacetate & 14.17 & 1255 & 104 & 91 & $103-45-7$ & RI, MS \\
\hline \multicolumn{7}{|l|}{ Alcohols } \\
\hline 2-methyl 1-butanol & 2.59 & 733 & 57 & 56 & $137-32-6$ & MS \\
\hline eucalyptol & 8.69 & 1032 & 108 & 154 & $470-82-6$ & RI, MS \\
\hline benzyl alcohol & 8.71 & 1033 & 79 & 108 & $100-51-6$ & RI, MS \\
\hline 1 alcohol & 10.93 & 1113 & 91 & 92 & $60-12-8$ & RI, MS \\
\hline (Z)-6-nonenol & 12.41 & 1171 & 67 & 95 & $35854-86-5$ & RI, MS \\
\hline (Z, Z)-3,6-nonadienol & NR & & & & $53046-97-2$ & \\
\hline nonanol & 12.45 & 1172 & 97 & 83 & $143-08-8$ & RI, MS \\
\hline benzenepropanol & 13.72 & 1232 & 91 & 117 & $122-97-4$ & RI, MS \\
\hline \multicolumn{7}{|l|}{ Aldehydes } \\
\hline hexanal & 3.37 & 801 & 82 & 56 & $66-25-1$ & RI, MS \\
\hline (E)-2-hexenal & 4.24 & 850 & 55 & 69 & $6728-26-3$ & RI, MS \\
\hline (Z)-3-hexenal & NR & & & & $6789-80-6$ & \\
\hline benzaldehyde & 6.80 & 962 & 105 & 106 & $100-52-7$ & RI, MS \\
\hline octanal & 7.87 & 1003 & 57 & 84 & $124-13-0$ & RI, MS \\
\hline benzeneacetaldehyde & 8.99 & 1043 & 91 & 120 & $122-78-1$ & RI, MS \\
\hline (E)-2-octenal & 9.40 & 1057 & 55 & 70 & $2548-87-0$ & RI, MS \\
\hline (Z)-6-nonenal & 10.65 & 1101 & 55 & 81 & $2277-19-2$ & RI, MS \\
\hline nonanal & 10.73 & 1104 & 57 & 98 & $124-19-6$ & RI, MS \\
\hline (E, Z)-2,6-nonadienal & 12.01 & 1155 & 70 & 69 & $557-48-2$ & RI, MS \\
\hline (E)-2-nonenal & 12.18 & 1162 & 55 & 70 & $18829-56-6$ & RI, MS \\
\hline$(E, Z)$-2,4-nonadienal & 12.99 & 1196 & 81 & 67 & $2363-88-4$ & MS \\
\hline$(E, E)$-2,4-nonadienal & 13.42 & 1216 & 81 & 138 & $5910-87-2$ & RI, MS \\
\hline (Z)-citral & 13.86 & 1240 & 69 & 94 & $106-26-3$ & RI, MS \\
\hline$(E)$-citral & 14.43 & 1270 & 69 & 94 & $141-27-5$ & RI, MS \\
\hline (E)-2-undecanal & 15.13 & 1306 & 70 & 83 & $112-44-7$ & RI, MS \\
\hline \multicolumn{7}{|l|}{ Sulfur-compounds and other } \\
\hline S-methyl thiobutanoate & NR & & & & $2432-51-1$ & \\
\hline 3-(methylthio)propanal & NR & & & & $3268-49-3$ & \\
\hline S-methyl 3-methylbutanethioate & 6.22 & 938 & 57 & 85 & $23747-45-7$ & MS \\
\hline ethyl 2-(methylthio)acetate & 7.32 & 981 & 61 & 134 & $4455-13-4$ & RI, MS \\
\hline methyl 3-(methylthio)propanoate & 8.45 & 1023 & 134 & 103 & $13532-18-8$ & MS \\
\hline ethyl 3-(methylthio)propanoate & 10.57 & 1098 & 74 & 148 & $13327-56-5$ & RI, MS \\
\hline 3-(methylthio)propyl acetate & 11.21 & 1123 & 88 & 73 & --- & MS \\
\hline (Z)-1,5-octadien-3-one & NR & & & & $65767-22-8$ & \\
\hline
\end{tabular}

${ }^{\bar{z}}$ CIFAC status based on Buttery et al. (1982), Horvat and Senter (1987), Kemp et al. (1972), Nussbaumer and Hostettler (1996), Schieberle et al. (1990), Wyllie et al. (1994, 1995), and Wyllie and Leach (1992)

${ }^{\mathrm{y}} \mathrm{RT}=$ retention time

${ }^{\mathrm{x}} \mathrm{RI}=$ in-house retention index (Beaulieu and Grimm, 2001).

${ }^{\mathrm{w}} \mathrm{T}$-ion $=$ target ion.

${ }^{\mathrm{v}} \mathrm{Q}$-ion $=$ qualifying ion

"DB-5 = crosslinked 5\% phenyl methyl silicone column

$\mathrm{m} / \mathrm{z}=$ mass to charge ratio

${ }^{\mathrm{s}} \mathrm{CAS}=$ Chemical Abstract Service

${ }^{\mathrm{r}} \mathrm{ID}=$ identification means used for designation; $\mathrm{RI}=$ retention index, $\mathrm{MS}=\mathrm{Wiley} 7^{\text {th }} / \mathrm{NIST} 02$ registry of mass spectra library (McLafferty, 2000).

${ }^{\mathrm{q}} \mathrm{NR}=$ not recovered
In cantaloupe, development of an abscission layer between the vine and fruit at the peduncle is a good indicator of full ripeness and harvest time. Fruit harvested before development of the abscission zone will not develop volatiles and flavor similar to fruit that remained on the vine until fully ripe (Beaulieu and Grimm, 2001; Pratt, 1971; Wyllie et al., 1996). However, fruit harvested at or after development of the abscission have a shorter storage life, and flavor or textural loss may occur before completion of the marketing process (Evensen, 1983; Ogle and Christopher, 1957). To deliver a longer shelf-life, the fresh-cut industry prefers to process less mature fruit, which are typically firmer. Reports documenting generation, change and/or loss of flavor and aroma in stored fresh-cut fruit are limited (Beaulieu and Baldwin, 2002; Beaulieu and Lea, 2003a, 2003b; Bett et al., 2001; Bett-Garber et al., 2003; Saftner et al., 2003). Subsequently, solid phase microextraction (SPME) and gas chromatographymass spectrometry (GC-MS) was utilized to study flavor volatile profiles in cantaloupe during growth, development, and in stored fresh-cuts prepared with different harvest maturities, in order to determine if processing maturity affects flavor volatile levels during storage.

\section{Materials and Methods}

ImMATURE PLANT MATERIAL. Orange-flesh netted cantaloupes (cv. Sol Real) were grown in Kettleman City, Calif. (year-1) and Five Points, Calif. (year-2), on raised beds with standard cultural practices in a commercial field with furrow irrigation. Roughly 4000 to 6000 flowers were tagged during anthesis in one morning during peak flowering. To ensure a higher percentage of fruit set, developing fruit proximal to tagged flowers were removed upon tagging. Developing fruit were harvested weekly for 4 weeks at $13,20,28$, and $35 \mathrm{~d}$ after anthesis (DAA) in June/July (year-1) and 13, 20,27, and 34 DAA in July (year-2). Fruit were field hydro-cooled in an ice-slurry, chilled $\left(\approx 5^{\circ} \mathrm{C}\right)$ until being packed with Styrofoam beads, and shipped overnight to the Southern Regional Research Center (SRRC, New Orleans, La.) for immediate analysis the following morning.

Mature Plant Material. One-quarter-slip fruit had a clearly green, well-attached peduncle, whereas 1/2-slip fruit had a distinct abscission layer detectable at the peduncle, roughly half way in the stem. Three-quarter-slip fruit (typical commercial harvest) were almost abscised at the peduncle, and full-slip (FS) fruit will cleanly separate from the vine with light pressure, or had just separated naturally. Over-ripeness was precisely categorized as $2 \mathrm{~d}$ past FS. Maturity was carefully monitored in the field by flagging tagged fruit at commercial harvest, 3/4-slip. In year-1, ripe fruit were harvested $38 \mathrm{DAA}$ at five distinct maturities [1/4-slip, 1/2-slip, 3/4-slip, FS, and over-ripe (OR)], field hydro-cooled, stored over the weekend at $\approx 5^{\circ} \mathrm{C}$, packaged as above and freighted to the SRRC for analysis. In year- 1,5 d elapsed between harvesting and fresh cutting. In year-2, ripe fruit were harvested 37 DAA, with 4 $\mathrm{d}$ storage at $\approx 5^{\circ} \mathrm{C}$ prior to fresh cutting. After observing little to no fungal or bacterial decay after $9 \mathrm{~d}$ storage in the first year, the fresh-cut shelf-life portion was extended in year-2 to $14 \mathrm{~d}$.

Fresh-CUT AND SAMPLe PREParation. Fruit were inspected carefully for bruising and compression damage and culled if not in optimum condition. Fruit were washed in cold running tap water then sanitized in $100 \mu \mathrm{L} \cdot \mathrm{L}^{-1} \mathrm{NaClO}(\mathrm{pH} \approx 6.7)$, rinsed in deionized water, and uniformly peeled using a melon peeler (CP-44; Muro Corp., Tokyo), except 13 DAA 'Sol Real' fruit, which were hand peeled with a carrot peeler. The stem and blos- 
som portions ( $\approx 2$ to $3 \mathrm{~cm}$ ) were removed, and each melon was sliced longitudinally. Seeds were removed and the seed cavity cleaned, halves were cut into roughly $2.5-\mathrm{cm}$ equatorial slices, from which all loose endocarp seed cavity tissue (1 to $2 \mathrm{~mm}$ thick) was removed. Approximately 2 to $3 \times 2.5-\mathrm{cm}$ cubes were prepared in pie-like wedges cut from the 2.5 -cm-wide slices (Beaulieu and Lea, 2003a). Processing was done under strict sanitary conditions, employing good manufacturing practices in a food preparation kitchen. For fresh-cut storage, cubes from numerous fruit (five to six per maturity) were randomized and roughly $300 \mathrm{~g}$ were randomly placed into $710-\mathrm{mL}$ (24 fl oz) low profile Juice Catcher containers (SRW-24-JC; Winkler Forming, Carrollton, Tex.). Fresh-cuts were stored at $4{ }^{\circ} \mathrm{C}$ and cubes were assessed from individual containers after $0,2,5,7,9,12$, and 14 d storage.

GC-MS VOLATILE SAMPLE PREPARATION. Volatile samples were prepared in triplicate, each from $300 \mathrm{~g}$ of randomized cubes from a representative pool of five to six immature fruit, or $300 \mathrm{~g}$ of randomized fresh-cut cubes from a minimum of five fruit per maturity, as previously described (Beaulieu and Grimm, 2001). Briefly, tissue was rapidly juiced $(\approx 15 \mathrm{~s})$ into a slurry with a juicer (Braun MP80; Gillette Co., Boston), a 3-mL slurry (without foam) was immediately pipetted into $10-\mathrm{mL}$ glass vials containing $1.1 \mathrm{~g}$ $\mathrm{NaCl}$, then 2-methylbutyl3-methylbutanoate internal standard(IS) was added. Vials were sealed with a steel crimp cap fitted with a Teflon/silicon septum, and placed on a Combi-Pal Autosampler (Leap Technologies, Carrboro, N.C.) cooling rack at $4{ }^{\circ} \mathrm{C}$.

Headspace SPME GC-MS analysis. Sample vials were equilibrated $10 \mathrm{~min}$ via oscillation in a $40{ }^{\circ} \mathrm{C}$ autosampler, then a $1-\mathrm{cm}, 100-\mu \mathrm{m}$ polydimethylsiloxane (PDMS) SPME fiber was inserted into the headspace for $12.5 \mathrm{~min}$ at $40{ }^{\circ} \mathrm{C}$. Volatile compounds were analyzed at approximately the temperature of the human palate, where mastication occurs $\left(\approx 37^{\circ} \mathrm{C}\right)$. Vials were continuously swirled during SPME adsorption with an agitation speed of $100 \mathrm{rpm}$. Fibers were desorbed at $250{ }^{\circ} \mathrm{C}$ for $1 \mathrm{~min}$ in the injection port of an GC-MS (HP6890/5973; Agilent Technologies, Wilmington, Del.) with a crosslinked, $5 \%$ phenyl methyl silicone column [30 m, $0.25 \mathrm{~mm}$ i.d., 25- $\mu \mathrm{m}$ film thickness (DB-5; J\&W Scientific, Folsom, Calif.)] for 30-min runs. The injection port was operated in splitless mode and subjected to a pressure of 172 $\mathrm{kPa}$ of ultra-high purity helium $(99.9995 \%)$ for the first minute, then flow velocity was constant at $40 \mathrm{~cm} \cdot \mathrm{s}^{-1}$ for the remainder of the $\mathrm{GC}$ run. The initial oven temperature was $50{ }^{\circ} \mathrm{C}$, held 1 min, ramped $5^{\circ} \mathrm{C} / \mathrm{min}$ to $100{ }^{\circ} \mathrm{C}$ then $10^{\circ} \mathrm{C} / \mathrm{min}$ to $250{ }^{\circ} \mathrm{C}$, and held $9 \mathrm{~min}$. The HP5973 quadrupole mass spectrometer was operated in the electron ionization mode at 70 electron volts, a source temperature of $200{ }^{\circ} \mathrm{C}$, with a continuous scan from mass to charge ratio $(\mathrm{m} / \mathrm{z}) 33$ to 300 . Year-2 GC-MS conditions were identical to year-1, except that cryofocussing $\left(-60^{\circ} \mathrm{C}\right)$ at the $\mathrm{GC}$ inlet was utilized as compounds were desorbed $(1 \mathrm{~min})$ from the SPME fiber atop the column.

Data ACQuisition AND PRocessing. Data were collected with HP ChemStation software (A.03.00; Agilent Technologies, Wilmington, Del.) and searched against the seventh edition

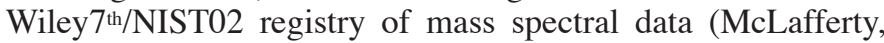
2000). Compounds were preliminarily identified by library search then their identity was confirmed by standard comparisons, GC retention time (RT), MS ion spectra and an in-house retention index (RI) (Beaulieu and Grimm, 2001). The RTs from a series of straight chain alkanes $\left(\mathrm{C}_{5}-\mathrm{C}_{20}\right)$ were used to calculate RIs for all identified compounds. The IS ion response was used to examine each run, and then each compound's integrated response was examined carefully via their selected unique target ion and qualifying ion (Q-ion) ratios (Table 1). Relative percent recovery was expressed per compound classes or compound as the target response divided by the total suite of 55 compounds positively identified per sample. Data were expressed as averaged target response or relative percentage for specified compounds or compound classes, in triplicate $(n=3)$, combined over the 2 years.

Sensory APPRAISAl. Five to six in-house scientists, trained according to the Spectrum method for descriptive sensory analysis (Meilgaard et al., 1999), assessed immature cantaloupe and various cucurbits according to in-house protocols (Bett-Garber et al., 2003). Cubes were equilibrated to room temperature in cups covered with watch glasses. Covers were slid back to allow the headspace to enter the nose. Aroma intensities emitted from the samples were evaluated then cubes were placed in the mouth and chewed to prepare for swallowing, but expectorated. Flavor and texture descriptor intensities were rated on a 0 to 15 point anchored scale, with $0=$ not detectable, and $15=$ more intense than most foods. If the flavor by mouth descriptor was observed with a different intensity than aroma, or vice versa, the evaluator recorded an estimated intensity average.

Statistical analysis. Data were analyzed using SAS Proc Mixed, SPlus (release 8.2; SAS Institute, Cary, N.C.). In order to evaluate volatile classes throughout the entire experiment, a comparison was made between immature and mature fruit volatiles, using treatment combinations as weeks after anthesis $\times$ maturity. DAA $\times$ maturity were combined as days after anthesis classified by weeks (DAA $=2,3,4,5,6,7$, and 8 weeks) and maturity $(0 \mathrm{Q}=$ immature, $1 \mathrm{Q}=1 / 4$-slip, $2 \mathrm{Q}=1 / 2$-slip, $3 \mathrm{Q}=3 / 4$-slip, $4 \mathrm{Q}$ $=\mathrm{FS}$, and $5 \mathrm{Q}=\mathrm{OR})$. Weeks were designated as 2 (13 DAA), 3 (20 DAA), 4 (27 and 28 DAA), 5 (34 and 35 DAA), 6 (day of fresh-cutting = day 0 and storage day 2), 7 (storage days 5, 7, and 9), and 8 (storage days 12 and 14). Subsequently, 19 unique treatments were created (2/0Q, 3/0Q, 4/0Q, 5/0Q, 6/1Q, 6/2Q, 6/3Q, 6/4Q, 6/5Q, 7/1Q, 7/2Q, 7/3Q, 7/4Q, 7/5Q, 8/1Q, 8/2Q, $8 / 3 \mathrm{Q}, 8 / 4 \mathrm{Q}$, and 8/5Q) and data were analyzed as a randomized block design where year was the block with a one-way treatment structure.

With mature fruit (harvest and fresh-cut storage), data were analyzed as a randomized complete-block design with a two-way treatment structure $(7 \times 5)$ with 7-d levels, $0,2,5,7,9,12$, and 14; and five maturity levels, 1Q (1/4-slip), 2Q (1/2-slip), 3Q (3/4-slip), 4Q (FS), and 5Q (OR). There were no measurements in year- 1 for days 12 and 14 . There were only day 0 measures in year-1 for OR. Each treatment combination had three replications (container was the experimental unit). Volatile classes were evaluated from harvest through fresh-cut storage by summing triplicates of each compound over both years, and generating linear equations. Slopes and intercepts were compared at the 95\% lower and upper confidence limits. The Tukey multiple comparison procedure was employed to evaluate mean differences when main effect or interaction means were statistically significant $(P<0.05)$. All multiple comparisons were conducted at the 0.05 level of significance.

\section{Results and Discussion}

Fifty-five compounds were integrated and used to assess volatile changes through cantaloupe maturation and during fresh-cut storage (Table 1). Within this group, 18 of the reported 24 CIFACs were routinely recovered and positively identified in 'Sol Real' cantaloupe using PDMS SPME GC-MS (Table 1). Certain com- 
pounds previously reported as aroma-important in cantaloupe, such as two $\mathrm{C}_{9}$ aliphatic acetates $[(Z) 6$-nonenyl acetate and $(Z, Z)$ 3,6-nonadienyl acetate] (Horvat and Senter, 1987), S-compounds [S-methyl thiobutanoate, 3-(methylthio)propanal] (Wyllie et al., 1994) and (Z)-3-hexenal and (Z)-1,5-octadien-3-one (Schieberle et al., 1990) were not observed in 'Sol Real'. However, with this method, recovery of certain compounds or isomers is cultivar dependent (Beaulieu and Grimm, 2001).

Quantification of volatiles and establishing trends with SPME in a complex matrix can be problematic. Under standard conditions (temperature, stirring, adsorption time, etc.), as the matrix concentrations or presence/absence of various analytes changes over time, there is differential loading onto a given fiber (Ai, 1998; Murray, 2001; Niedziella et al., 2000; Rocha et al., 2001). Within a solution being analyzed, concentration changes in naturally occurring and/or added compounds (sugars, salts, pectin, citric acid, and phosphoric acid) can reduce or increase specific analyte recoveries (Bezman et al., 2003; Hansson et al., 2001a, 2001b). In addition, each SPME fiber type has limitations with regard to which classes of compounds are readily absorbed. Several different PDMS fibers were utilized over the course of this study, and there is recovery variability over time on a given fiber (Niedziella et al., 2000). In order to correctly quantify volatiles with standards using SPME, the concentration and identity of every component that might displace low molecular weight compounds from the fiber in a sample should be known (Murray, 2001; Niedziella et al., 2000). Volatile trends observed in selected ion abundance over both years were consistent. However, due to the aforementioned items, relative percentages were generally used to present the data and avoid erroneous quantification in this complicated headspace matrix. Nonetheless, trends for selected ion abundance were generally very similar compared with relative percentage trends.

Using an analysis of data, as weeks after anthesis from 13 DAA through the end of the fresh-cut study (55 DAA), all volatile classes changed significantly during growth and development through the fresh-cut storage portion (Table 2). There were significant yearly variations found for all the volatile classes except for aldehydes and total esters. This is not surprising, as numerous environmental and physiological events can alter volatile levels, and this was statistically expected. The volatile trends were generally conserved over years. All treatment combinations (DAA $\times$ maturity) for each volatile class displayed significant changes from the immature anthesis-tagged stage through to the fresh-cut portion (Table 2 ). The total volatiles and most classes (except aldehydes) had insignificant changes during the immature periods (weeks 2-5); however, there were clearly significant differences in week 6, corresponding to the harvest maturity upon processing, on day 0 . Significant maturity-dependent differences were observed in the following weeks 7 and 8, corresponding to fresh-cut storage. These data are therefore addressed separately below.

\section{Volatile trends in immature fruit}

Total ion traces for volatiles recovered in fruit harvested during growth and development (i.e., 13 to 35 DAA) clearly illustrate changes in volatiles through to commercial harvest (Fig. 1 ). Very little to no esters, acetates, or alcohols were recovered in immature fruit $(13,20$, and 28 DAA). Most flavor-related esters and acetates were absent until 4 weeks after anthesis at 27 or 28 DAA, corresponding with physiological maturity. As fruit approached horticultural maturity (34 or 35 DAA), esters and acetates became dominant. Nonetheless, in the fourth week after anthesis, the relative amounts of CIFACs were substantially lower compared with 10 d later, at harvest. As maturity increased, a progressive increase in concentration was observed in most cantaloupe volatiles recovered (Fig. 1). This general trend has been reported previously (Beaulieu and Grimm, 2001; Horvat and Senter, 1987; Yabumoto et al., 1978).

Utilizing the PDMS fiber with this method, $99.8 \%$ to $99.9 \%$ of all compounds recovered (based on both target response and relative percentage) through 27 or 28 DAA were aldehydes (Fig. 2). On an absolute basis, the recovery of 15 aldehydes (Table 1) increased during growth and development through 28 DAA then declined sharply by harvest of the various maturities at 37 or 38 DAA. Numerous aldehydes have been reported in other Cucurbitaceae such as bittermelon (Momoridica charantia L.), cucumber(Cucumis sativus L.), and watermelon(Citrullus lanatus Thunb.) (Binder et al., 1989; Fleming et al., 1968; Yajima et al., $1985)$; and (Z)-3-hexenal and (E)-2-hexenal were attributed to the "green notes" in C. melo (Schieberle et al., 1990). In year-1, four scientists observed that only immature cantaloupe (13 and 20 DAA) smelled and tasted like cucumber. Therefore, in the second year, five to six in-house scientists trained in descriptive sensory analysis compared various cucurbits to 'Sol Real' cantaloupe. Immature anthesis-tagged 'Sol Real' was compared during growth and development against store-bought cucumber, zucchini (Cucurbita pepo L.), and two field-harvested ripe cantaloupe cultivars ('Sol Real' and 'Athena'). Immature (13 and 20 DAA) cantaloupe smelled and tasted like cucumber, with characteristic "cucurbit/pumpkin" notes. Both "cucurbit/pumpkin" (Fig. 3A) and "green" (Fig. 3B) notes decreased as the cantaloupe fruit developed, whereas ripe cantaloupe consistently had the lowest intensity scores for these attributes. Cucumber, zucchini, and immature cantaloupe were scored highest in these undesirable attributes, as well as "astringent" (data not shown). A decrease in these undesirable sensory attributes paralleled decreased GC-MS recovery of aldehydes (Fig. 2). Concomitantly, mature cantaloupe scored highest for "sweet" (Fig. 3C) and "fruity" (data not shown), with immature melons only having desirable attributes after 27 DAA, when aldehyde levels began a precipitous decrease (Fig. 2).

The SPME GC-MS aldehyde data and informal sensory results indicate this volatile extraction method is worthy for use in cantaloupe flavor analysis because "green" notes or flavors associated with aldehydes and potential oxidative by-products were only prevalent in immature cantaloupe and other nonsweet, typically "green" tasting cucurbits. By harvest (corresponding with 34 and 35 DAA), aldehydes such as pentanal, hexanal, octanal, nonanal, $(E)$-2-hexenal, $(E)$-2-nonenal, $(Z)$-6-nonenal, $(E, Z)$-2,6-nonadienal, and benzaldehyde were still present. At this time however, $(E, Z)$-2,6-nonadienal and $(E)$-2-nonenal were the prevailing aldehyde volatiles recovered which, are CIFACs. Simultaneously, at 34 and 35 DAA, numerous esters such as methyl 2-methylbutanoate, 2-methylpropyl acetate, benzyl acetate, 2-methylbutyl acetate, 2-methylpropyl acetate, hexyl acetate, (Z) 3-hexenyl acetate, and ethyl phenylacetate, some of which are CIFACs, dominated (of the top 11 compounds) the overall aroma profile.

\section{Volatile trends at harvest}

The integrated target responses (based on selected qualifying ion abundances) and relative percentages for various compounds recovered from fruit harvested at five distinct maturities in year1 , and four maturities in year-2, indicated clearly significant 
Table 2. Analysis of variance $\mathrm{F}$ values and probabilities for relative percentage of solid phase microextraction, gas chromatograph-mass spectrometry volatile classes ${ }^{\mathrm{z}}$ during maturation through fresh-cut storage in cantaloupes.

\begin{tabular}{lrrrr}
\hline & \multicolumn{2}{c}{ Year } & \multicolumn{2}{c}{ Treatment $^{\mathrm{y}}$} \\
\cline { 2 - 5 } & \multicolumn{1}{c}{$\mathrm{F}$} & $P^{\mathrm{x}}$ & \multicolumn{1}{c}{$\mathrm{F}$} & \multicolumn{1}{c}{$P$} \\
\hline Aldehydes & 0.151 & 0.698 & 165.905 & $<\mathbf{0 . 0 0 1}$ \\
Nonacetate esters & 81.082 & $<\mathbf{0 . 0 0 1}$ & 61.667 & $<\mathbf{0 . 0 0 1}$ \\
Acetates & 55.083 & $<\mathbf{0 . 0 0 1}$ & 37.767 & $<\mathbf{0 . 0 0 1}$ \\
Total esters & 0.249 & 0.619 & 169.372 & $<\mathbf{0 . 0 0 1}$ \\
Aromatics & 51.423 & $<\mathbf{0 . 0 0 1}$ & 7.338 & $<\mathbf{0 . 0 0 1}$ \\
Total aromatics & 46.277 & $<\mathbf{0 . 0 0 1}$ & 9.302 & $<\mathbf{0 . 0 0 1}$ \\
Alcohols & 4.976 & $\mathbf{0 . 0 2 9}$ & 5.901 & $<\mathbf{0 . 0 0 1}$ \\
Sulfur compounds & 56.265 & $<\mathbf{0 . 0 0 1}$ & 28.943 & $<\mathbf{0 . 0 0 1}$ \\
\hline
\end{tabular}

${ }^{\mathrm{z}}$ Individual volatile compounds comprising each class are listed in Table 1

${ }^{\mathrm{y}}$ Treatments, days after anthesis (DAA) $\times$ maturity, are a combination of DAA classified by weeks (DAA $=2,3,4,5,6,7$, and 8 weeks) and maturity (immature, 1/4-slip, 1/2-slip, 3/4-slip, full-slip, and over-ripe), according to the materials and methods.

${ }^{x}$ Probabilities with significance, $\alpha \leq 0.05$, and in bold type.

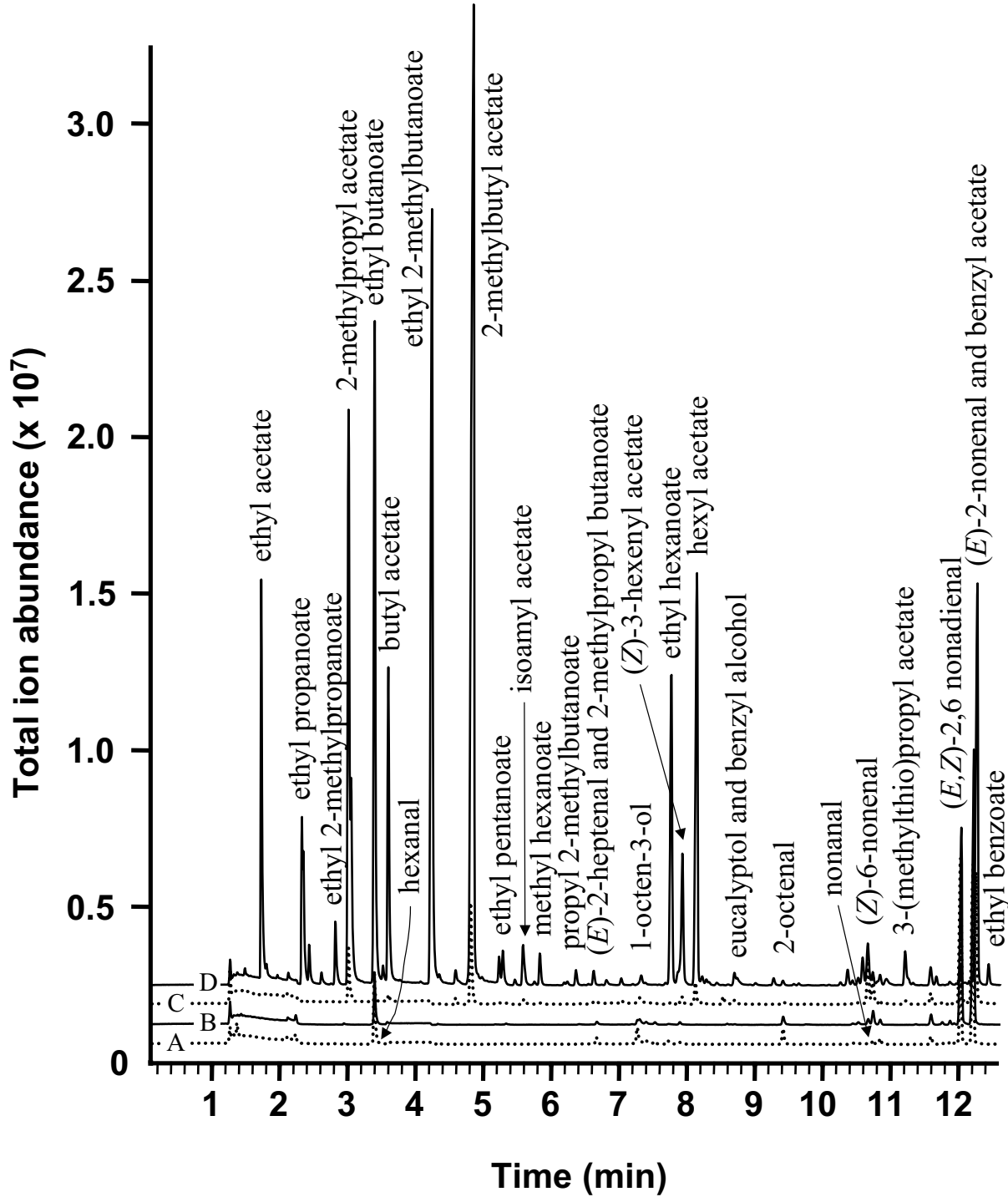

Fig. 1. Total ion chromatograms (solid phase microextraction, gas chromatograph-mass spectrometry) for anthesis-tagged 'Sol Real' cantaloupe fruit during development at (A) $13 \mathrm{~d}$ after anthesis (DAA), (B) 20 DAA (C) $35 \mathrm{DAA}$, and (D) $38 \mathrm{DAA}$ (corresponds with 3/4-slip harvested fruit). Each chromatogram was offset by 625,000 counts. One of the three replicate runs, which were nearly identical, was presented per maturity. maturity-dependent trends. Recovery for each class of compounds (acetates, nonacetate esters, total esters, aromatics, alcohols, and S-compounds) and most individual volatiles, followed a trend where FS > 3/4-slip > 1/2-slip > 1/4-slip. Immediately after harvest, upon processing, only $70.0 \%, 37.7 \%$, and $20.5 \%$ total volatiles (target response) were recovered in 3/4-slip, 1/2-slip, and1/4-slip fruit, compared to full-slip fruit. Total volatile profiles displayed a linear increase [integrated ion abundance $=113,026,149$ (slip) $\left.-11,122,890 ; R^{2}=0.985\right]$ that was maturity-dependent, where FS $(104,314,325)$ $>3 / 4$-slip $(73,046,433)>1 / 2$-slip $(39,357,564)>1 / 4$-slip $(21,355,491)$ (Fig. 4). Likewise, total esters displayed a linear increase [integrated ion abundance $=111,285,256$ (slip) $+-12,438,670 ; R^{2}=$ $0.984]$ which was maturity-dependent, where FS $(101,184,481)>3 / 4$-slip $(70,660,505)>1 / 2$-slip $(36,919,810)$ $>$ 1/4-slip $(19,693,666)$ (Fig. 4). These data indicate that the vast majority of compounds observed with this method were esters. Utilizing target response, it was deduced that $92.2 \%, 93.8 \%, 96.7 \%$, and $97.0 \%$ of the total volatiles were esters in 1/4-slip, 1/2-slip, 3/4-slip, and FS, respectively. In addition, the mean percent total esters were statistically different $(P$ $=0.05)$ for $1 / 4$-slip $(95.0 \%)$ vs. all other maturity levels on day 0 . The relative "green nature" of less mature fruit can be assumed since aldehydes comprised $5.7 \%, 4.2 \%, 1.6 \%$, and $1.3 \%$ of the total volatiles for 1/4-slip, 1/2-slip, 3/4-slip, and FS, respectively. We previously reported that numerous flavor-related compounds such as methyl 2-methylbutanoate, ethyl butanoate, ethyl2-methylbutanoate, hexyl acetate, $(Z)$-6-nonenal, $(E)$-2-nonenal, $(E$, $Z$ )-2,6-nonadienal, and benzyl acetate significantly decreased when fruit were harvested OR (Beaulieu and Grimm, 2001).

Interesting differences in volatiles were observed by comparing the specific types of ester compounds recovered. Esters can be termed differently as "nonacetate esters" and "acetates" based upon their biosynthetic differences. Volatile esters, that are important contributors to the aroma of many fruit, are formed by esterification of alcohols, normally utilizing a CoA moiety or CoA-ester as the acyl donor (Harada et al., 1985; Pérez et al., 1996; Shalit et al., 2001; Ueda et al., 1997). For the sake of clarity, a nonconventional chemical nomenclature will be used, opposed to an ester designated as 


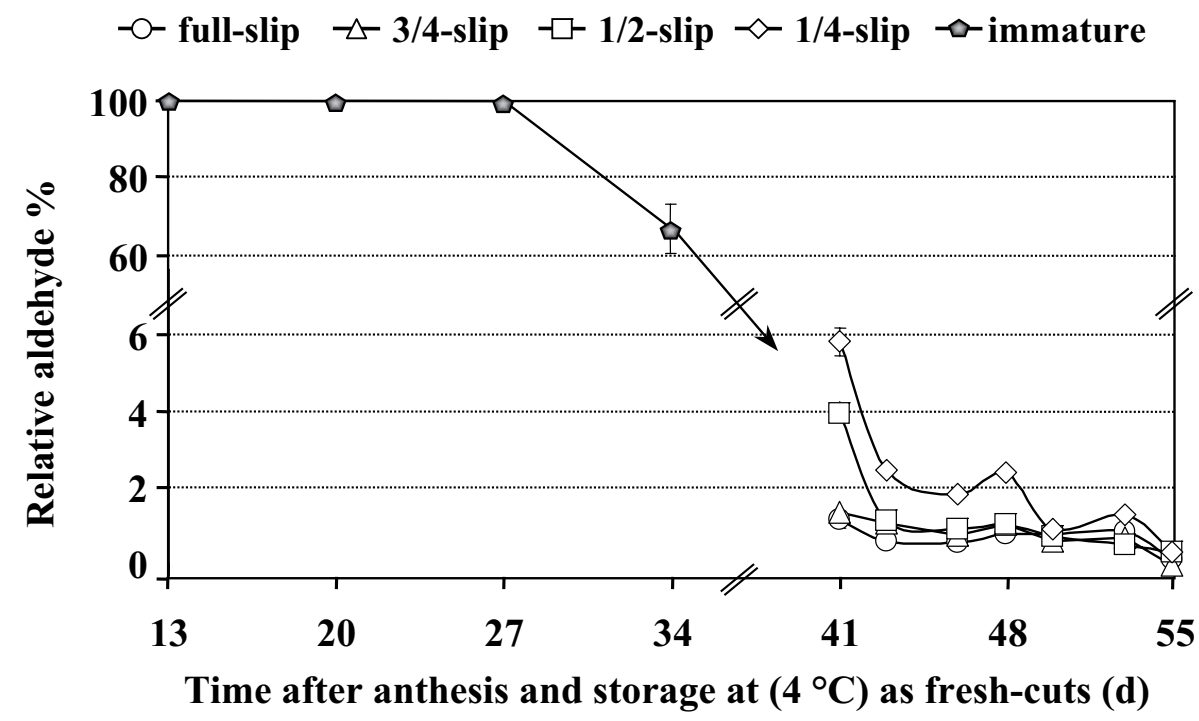

Fig. 2. Relative percent recovery of 15 aldehyde compounds out of the total 55 compounds integrated, according to Table 1, recovered via solid phase microextraction, gas chromatograph-mass spectrometry in cantaloupe throughout growth, development and during fresh-cut storage $\left(4{ }^{\circ} \mathrm{C}\right)$. The arrow and $\mathrm{x}$-axis double lines represent breaks between the last immature harvest vs. the various harvest maturities. Triplicate data were combined over 2 years. Standard error (SE) bars seldom extended beyond the graphed data points.

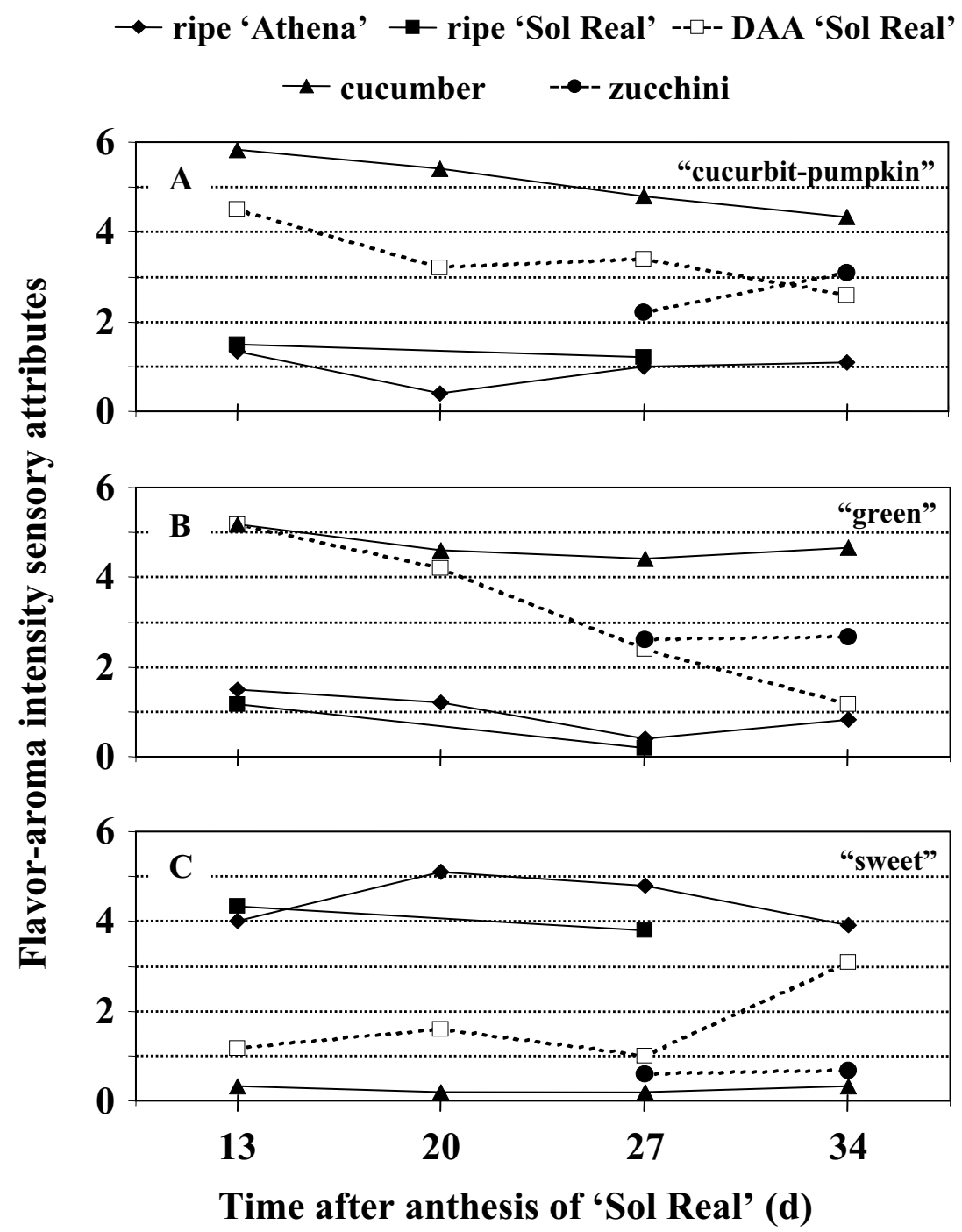

$\mathrm{R}^{\prime} \mathrm{C}(=\mathrm{O}) \mathrm{OR}$. It is generally believed that a flavor ester is enzymatically formed via alcohol acetyltransferase (AAT) esterification of an acyl moiety containing a positively charged polar carboxylic group (designated as $R_{\text {acid }}$ ), and an organic moiety (designated as $\mathrm{R}$ ). Subsequently, an "ester" has the basic structure $\left[\mathrm{R}_{\text {acid }} \mathrm{C}(=\mathrm{O})-\mathrm{OR}\right]$. "Acetates" are those esters formed when an acetate ion (acyl group) is the terminal $\mathrm{R}_{\text {acid }}$ attached at the carboxylic group via an ester bond (-), and is thereby represented as $\left[\mathrm{CH}_{3}-(\mathrm{C}(=\mathrm{O})-\mathrm{OR}\right.$ ].

ACETATES. Eleven ester compounds were isolated, analyzed and grouped as acetates (Table 1). At commercial harvest (37 or 38 DAA), 2-methylbutyl acetate and 2-methyl propyl acetate were the most abundant compounds recovered (via selected ion response) in 3/4-slip and full-slip fruit. In addition, ethyl acetate, propyl acetate, butyl acetate, hexyl acetate, (Z) 3-hexenyl acetate, and benzyl acetate generally dominated the volatile profiles (of the top 15 compounds recovered). Acetate profiles displayed a maturity-dependent linear increase [integrated ion abundance $=53,729,199$ (slip) $\left.+3,046,120 ; R^{2}=0.992\right]$ based on target response where 1/4-slip < 1/2-slip < 3/4-slip $<$ FS (Fig. 4). Furthermore, mean percent acetate levels were significantly different $(P=0.05)$ for $1 / 4$-slip (70\%) vs. OR $(39 \%)$ on day 0 . Acetates are often considered the most important class of volatiles, imparting fruit their unique and characteristic aroma and flavor, especially in Galia- or Charentais-type fruit (Bauchot et al., 1998; Shalit et al., 2001). Eastern-type U.S. cantaloupe fruit ('Athena') had more acetates, including unsaturated alkenyls of higher molecular weight, compared with U.S. western shipper cantaloupe ('Sol Real') (Beaulieu, 2005; Beaulieu and Grimm, 2001). Moreover, it has been found that butyl acetate, 2-methylbutyl acetate and hexyl acetate were the most abundant compounds in Galia-type melons (Fallik et al., 2001). Acetate concentrations have also been found to increase markedly with increasing maturity in apple (Malus $\times$ domestica Borkh.) and pear (Pyrus communis L.) fruit (Fellman et al., 2000; Shiota, 1990). Correspondingly, 11 acetates accounted for the majority ( $55.1 \%$ to $88.1 \%$ ) of

Fig. 3. (Left) Informal descriptive sensory analysis of flavors and aromas in various cucurbits. Panel A = "cucurbit pumpkin," B = "green," and C = "sweet." Data points are the average of $n=5$ or 6 . Days after anthesis (DAA) corresponds to the time after anthesis during growth and development of immature tagged 'Sol Real' cantaloupe. Weekly comparisons were with two field-harvested ripe cantaloupe cultivars (Sol Real and Athena) and store bought cucumber and zucchini. 


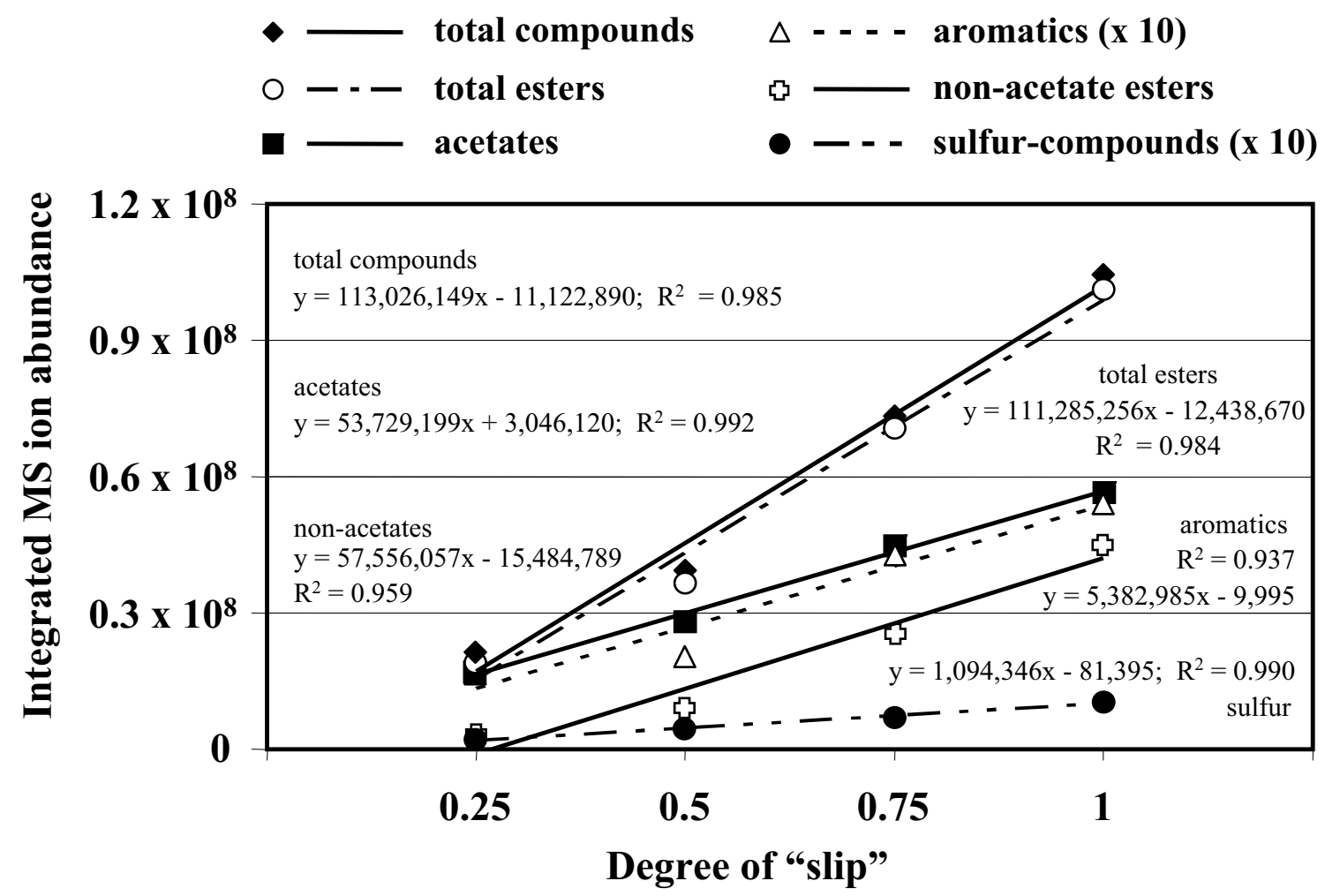

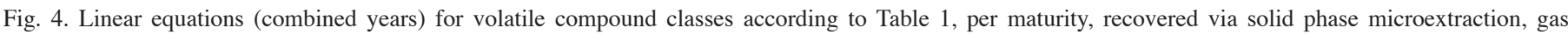

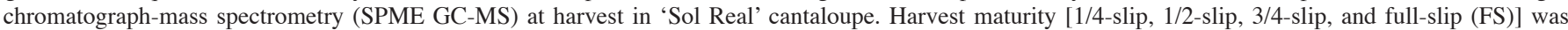

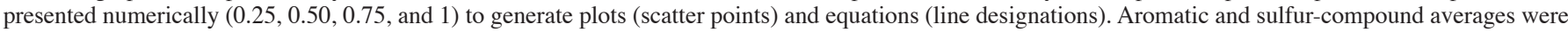
multiplied by 10 for graphing, but equations presented are numerically correct.

the total ester abundance at harvest across all maturities (excluding OR), whereas the 17 nonacetate esters (below group) accounted for less than one half (11.9\% to $44.9 \%)$ the total esters.

NonaCETATE ESTERS. Seventeen compounds not containing a methyl group at their R' terminus were designated as nonacetate esters (Table 1). The following nonacetate esters were amongst the top 15 compounds recovered in fruit harvested on 37 or 38 DAA: ethyl propanoate, ethyl butanoate, methyl 2-methylbutanoate, ethyl 2-methylbutanoate, and ethyl hexanoate. Nonacetate esters also displayed a strictly conserved maturity-dependent linear increase over maturity [integrated ion abundance $=57,556,057$ (slip) $\left.-15,484,789 ; R^{2}=0.959\right]$, where $1 / 4$-slip $(21,355,491)<1 / 2$-slip $(39,357,564)<3 / 4$-slip $(73,046,433)<$ FS $(104,314,325)$ (Fig. 4). Within the dominant esters recovered at harvest (the most abundant 15 compounds), three acetates and four nonacetate esters are considered CIFACs (Table 1).

Nonacetate ESTER: ACETATE Ratios. All maturity levels, with the exception of OR, had a greater percentage of acetates at harvest than percentage of nonacetate esters. On day 0,1/4-slip had the smallest ratio of nonacetate esters:acetates $(0.14)$ and OR had the largest ratio (1.48) and these two intercepts were statistically different $(P=0.05)$. Ratio differences per maturity, and likely importance of these ratios, will be discussed below.

Aromatic (BenZYL) COMPOUNDS. Eight benzyl compounds (benzyl acetate, ethyl phenylacetate, phenylethyl acetate, benzyl alcohol, phenyl ethyl alcohol, benzenepropanol, benzaldehyde, and benzeneacetaldehyde) were identified and classified together. Aromatic compound trends displayed a maturity-dependent linear increase [integrated ion abundance $=5,382,985$ (slip) $-9,995 ; R^{2}$ $=0.937$ ] based on target response where 1/4-slip $(1,685,239)<$ 1/2-slip $(2,031,723)<3 / 4$-slip $(4,278,332)<$ FS $(5,422,190)$ (Fig.
4). Furthermore, mean percent aromatic levels were significantly different $(P=0.05)$ for $1 / 4$-slip $(7.2 \%)$ vs. OR $(3.7 \%)$ on day 0 . Most aromatic compounds are mainly derived from the amino acid L-phenylalanine. Various ring substitution via hydroxylation and methylation steps result in acids that can be activated as their corresponding esters of $\mathrm{CoA}$. These activated benzoyl-CoA esters can enter various pathways, forming benzoic acid esters or benzaldehyde and alcohols (Gross, 1981). Although aromatic compounds are frequently important flavor components in other fruit, only one of these compounds (benzyl acetate) has been considered a CIFAC in melons.

Sulfur Compounds. Five S-compounds, three of which are CIFACs (Table 1), were grouped together: Again, there was a maturity-dependent linear increase [integrated ion abundance $=$ $1,094,346$ (slip) $\left.-81,395 ; \mathrm{R}^{2}=0.990\right]$ based on target response where 1/4-slip $(214,865)<1 / 2$-slip $(454,805)<3 / 4$-slip $(693,288)$ $<$ FS $(1,047,326)$ (Fig. 4). Various related sulfur compounds have been considered important in numerous $C$. melo cultivars (Horvat and Senter, 1987; Wyllie and Leach, 1992; Wyllie et al., 1994). Olfactometry sniffer port analysis revealed that numerous S-containing compounds had characteristic odors, but they were not "character impact" compounds (Wyllie and Leach, 1990). The structure of most S-containing compounds suggests that they are derived from methionine (Wyllie and Leach, 1992; Wyllie et al., 1994), possibly by the same pathway associated with ethylene biosynthesis (Yang and Hoffman, 1984). The maturity-dependent increase in S-compounds supports the notion that formation and presence of these compounds is closely associated with the endogenous level of ripening (or ethylene) at harvest, especially since abundance of sulfur compounds dropped off slightly $(705,024)$ in OR fruit. 
Alconols. Seven alcohols were recovered, even though the PDMS SPME fiber is not well suited for alcohol recovery. A maturity-dependent increase in alcohols, conserved over maturity, was observed where 1/4-slip $(223,384)<1 / 2$-slip $(338,387)<$ $3 / 4$-slip $(523,964)<$ FS $(713,359)$. However, OR fruit had markedly higher alcohol recovery $(1,464,147)$ compared with all other maturities. Increased alcohol production is often associated with senescence in fruit.

\section{Volatile analysis in stored fresh-cuts}

Total eSTERS (NONACETATE ESTERS PLUS ACETATES). Based on target responses for monitored ions of individual compounds, summed across compound classes, a maturity-dependent volatile recovery trend (except for aldehydes) generally occurred in both years for most dominant esters throughout fresh-cut storage where 1/4-slip < 1/2-slip < 3/4-slip < FS (Fig. 5). Occasionally, FS was greater then OR, and OR generally did not conserve a maturitydependent status relative to the other maturities during fresh-cut storage. Total esters, nonacetate esters and acetates displayed the same general trend during storage, a transient increase through 5 to $7 \mathrm{~d}$, followed by decreases by day 12 (Fig. 5). This trend appeared to be more pronounced as maturity increased, with the exception of fresh-cuts prepared from OR harvested fruit.

The percent total esters followed an increasing linear trend that was maturity-dependent. The magnitude of the slope decreased with maturity $(1 / 4$-slip $=0.382$ to $\mathrm{OR}=0.045)$; an indication that the effect of storage time decreased as the maturity increased. This was established by the slope estimates for FS and OR, which were not statistically different from $0(P=0.443$ and 0.396 , respectively). Mean percent total esters was statistically different $(P=0.05)$ for $1 / 4$-slip $(92.2 \%)$ vs. all other maturity levels at day 0 , but by day 7 the five maturity levels were not statistically different $(P>0.05), 1 / 4$-slip $=96.3 \%, 1 / 2$-slip $=97.2 \%, 3 / 4$-slip $=97.1 \%, \mathrm{FS}=97.3 \%$, and $\mathrm{OR}=97.2 \%$.

Marked total ester losses (based on MS total peak area) were recently reported in stored $\left(4^{\circ} \mathrm{C}\right)$ thin-sliced $(\approx 1 \mathrm{~mm})$ cantaloupe and pineapple [Ananas comosus (L.) Merr.] tissue (Lamikanra and Richard, 2002, 2004; Lamikanra et al., 2003). However, when cut according to industry standards $\left[\approx 2.5 \mathrm{~cm}^{3}\right.$ (fruit wedges)], similar short-term volatile losses were generally not observed in stored fresh-cut apple (Bett et al., 2001), cantaloupe (Beaulieu and Baldwin, 2002; Beaulieu and Lea, 2003a; Beaulieu et al., 2004), honeydew (C. melo var. inodorus Naud.) (Saftner et al., 2003), mango (Mangifera indica L.) (Beaulieu and Lea, 2003b), or pineapple (Spanier et al., 1998). In this study with cantaloupe cubes prepared according to industry standards, precipitous shortterm (e.g., 1 to $3 \mathrm{~d}$ ) total ester losses were not observed over two seasons with hundreds of stored fresh-cut samples prepared from five harvest maturities (Fig. 5). Excessive wounding in thin-sliced tissue likely accelerated aging and compromised physiological and enzymatic reactions, which led to radically different results compared with this study and the literature.

ACETATES. In year-1 there was a maturity-dependent acetate recovery, and all maturities lost $\approx 15 \%$ acetates through 9 -d freshcut storage. The maturity-dependent trend was conserved in year2 , yet cantaloupes at all maturity stages lost $20 \%$ (FS) to $50 \%$ (1/4-slip) of their acetate fraction after $5 \mathrm{~d}$ in storage. Based on target response over both years, acetate levels remained somewhat stable between days 0-7 and did not markedly change until after $7 \mathrm{~d}$ storage, across all maturities (Fig. 5). When combining all maturities, there was a $74.6 \%$ decrease in acetate levels after 12 $\mathrm{d}$ storage. There was a maturity-dependent decreasing curvilinear decrease in the relative percentage of acetates through storage, for the combined four "slip" maturities [relative percentage = $0.166(\text { days })^{2}-4.883$ (days) $\left.+64.563 ; R^{2}=0.945\right]$. The magnitude of the slope decreased with maturity $(1 / 4$-slip $=3.108$ to OR $=$ $1.137)$; an indication that the effect of storage time decreased as the maturity increased (Fig. 6). All slope estimates were statistically different from $0(P<0.01)$. Mean percent of acetates was statistically different $(P=0.05)$ for $1 / 4$-slip vs. OR on day 0 , but by day 12 , the mean percent acetates for the five maturity levels were not statistically different $(P=0.05)$. Not including OR, acetates comprised roughly $66.9 \%$ of all compounds recovered on day 0 yet, only $26.1 \%$ to $44.2 \%$, and $21.3 \%$ to $32.6 \%$ remained on days 9 and 14, respectively (Fig. 6).

NonACETATE ESTERS. In the first year, there was a maturitydependent nonacetate ester recovery, and a $14.0 \%$ (FS) to $20.0 \%$ (1/4-slip) increase in the recoveries in all maturities through $9 \mathrm{~d}$ fresh-cut storage. The maturity-dependent trend was conserved in the second year, with a maturity-dependent overall increase in esters through $14 \mathrm{~d}$ storage. A curvilinear increase in relative percentage of nonacetate esters, through storage, for all maturities $\left[\right.$ relative percentage $=-0.178(\text { days })^{2}+5.230($ days $)+30.675 ; R^{2}=$ 0.945], was observed (Fig. 7). Aside from OR, nonacetate esters comprised from $10.9 \%$ to $43.4 \%$ of all compounds recovered on day 0 , and these percentages increased to $53.1 \%$ to $64.0 \%$, and $65.3 \%$ to $73.2 \%$ on days 9 and 14 , respectively. Interestingly, a significant $(P=0.00)$ increase in nonacetate esters occurred in OR-harvested fruit. Anecdotal wisdom indicates that over-ripe or senescing fruit is often considered "flat" tasting or lacking the characteristic "fruity" attributes. Subsequently, these data indicate that certain esters that are likely unimportant with regard to acceptable flavor dominate the profile in OR fruit, and through storage.

NonACETATE ESTER: ACETATE RATIOS. There was an increasing linear trend for the ratio of nonacetate esters to acetates, an indication that over storage time, percent nonacetate esters increased as the percent acetates decreased. All maturity levels with the exception of OR had a greater percentage of acetates on day 0 than percentage of esters. At processing and throughout storage, the intercepts for 1/4-slip vs. OR were statistically different $(P$ $=0.05)$. A curvilinear nonacetate ester $:$ acetate response $[$ ratio $=$ $-0.012(\text { days })^{2}+0.227$ (days) $\left.+0.458 ; R^{2}=0.969\right]$ was observed when the four complete data sets for maturity (less OR) were combined through $9 \mathrm{~d}$ storage (Fig. 8). In addition, by day 14, 1/4-slip had the smallest ratio of nonacetate ester:acetates (2.02) and OR had the largest ratio (3.55) and these estimates were statistically different $(P=0.05)$. The slopes for the maturity levels were not statistically different throughout storage, an indication that the rate of change between the nonacetate esters and acetates was the same across all maturity levels. This provides evidence that there is a uniform change in the ester balance through fresh-cut storage that is independent of initial processing maturity.

Upon processing, the combined nonacetate ester:acetate ratio for all four repeated maturities (less OR) was 0.46 . The overall ester balance changed roughly 2 -fold after just $2 \mathrm{~d}$ at $4{ }^{\circ} \mathrm{C}$, increasing to 0.85 , and after $5 \mathrm{~d}$ it increased more than 3 -fold, to 1.40 (Fig. $8)$. There was not a correspondent decrease in the total volatile target response (55 compounds) during this time period (e.g., Fig. $5)$. This indicates that there was a shift in the balance of ester types through fresh-cut storage. Accordingly, one might anticipate changes in sensory attributes because decreases in the relative proportion of CIFAC acetates might decrease associated notes such as apple, banana, candy, cherry, citrus, floral, fragrant, fresh, 


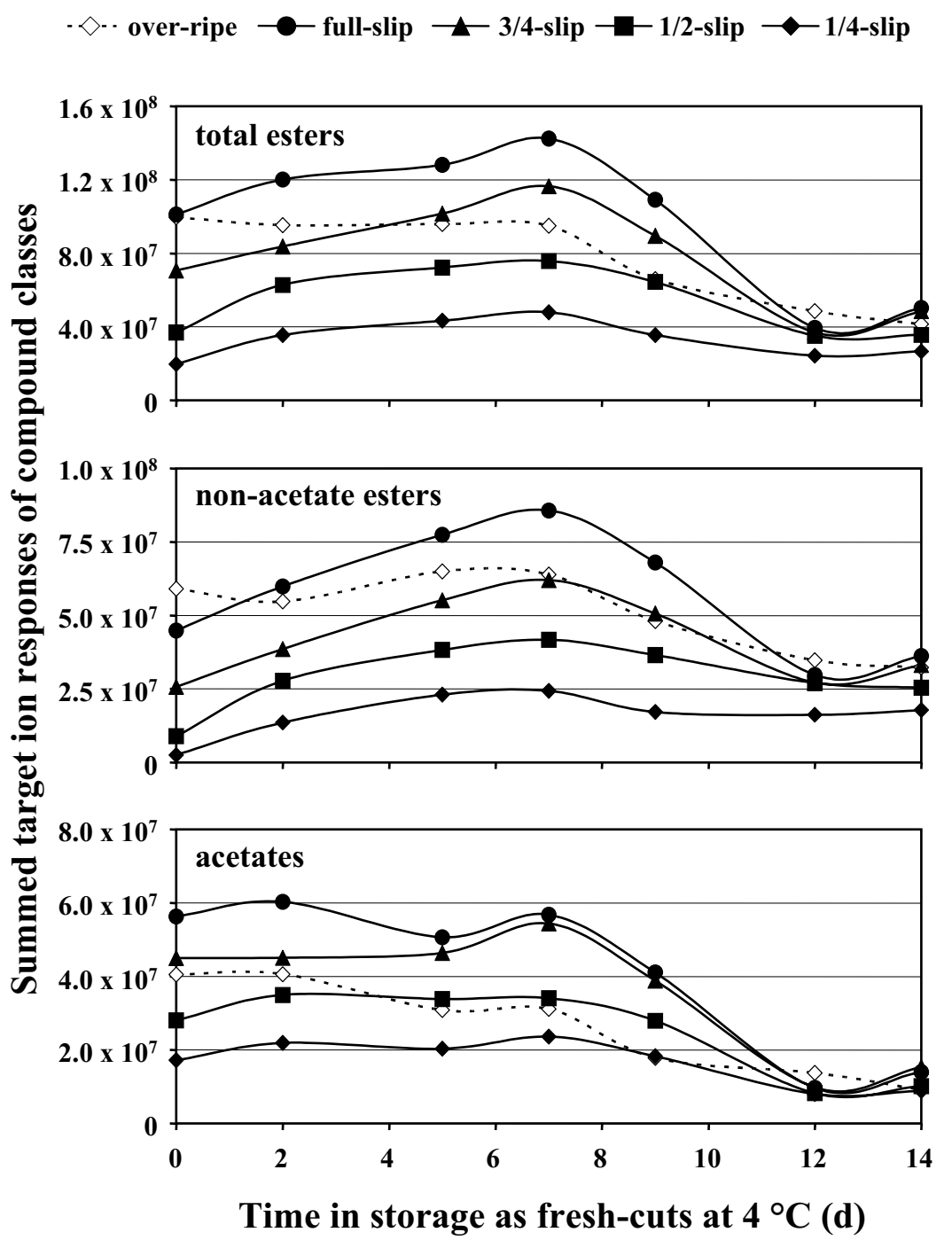

Fig. 5. Summed solid phase microextraction gas chromatograph-mass spectrometry target ion responses (combined years, based on monitored ions of individual compounds) for total ester, nonacetate ester, and acetate compound classes recovered in stored $\left(4{ }^{\circ} \mathrm{C}\right)$ fresh-cut cantaloupe prepared from 5 distinct maturities: 1/4-slip, 1/2-slip, 3/4-slip, full-slip (FS), and over-ripe (OR). Compounds used to generate classes are denoted in Table 1.

fruity, honeydew melon, pear, and sweet (Beaulieu, 2005; J.C. Beaulieu, unpublished). On the other hand, increases or excessive levels of certain nonacetate ester CIFACs have been associated with notes such as artificial strawberry, brandy, diffusive, ethereal, green, powerful, pungent, tutti frutti, and winey (Beaulieu, 2005; J.C. Beaulieu, unpublished). Nonetheless, sensory aspects and changes in the aroma and texture that occurred throughout these analyses were detailed elsewhere (Beaulieu et al., 2004).

Aromatic (Benzyl) compounds. Percent total aromatics followed a decreasing linear trend that was maturity-dependent. The magnitude of the slope decreased with maturity $(1 / 4-\mathrm{slip}=$ -0.418 to $\mathrm{OR}=-0.122$ ). This indicates that the effect of storage time decreased as maturity increased. This was established in the slope estimate for OR which, was not statistically different from $0(P=0.0859)$. The mean percent total aromatics in $1 / 4$-slip vs. OR cubes were statistically different $(P=0.05)$ on day 0 , but by day 7 , there were no statistical differences $(P>0.05)$ for the five maturity levels.

Sulfur Compounds. Based on selected ion monitoring, the five sulfur compounds increased as harvest maturity increased in both years. However, a maturity-dependent trend was only observed in year- 1 on a relative percentage basis. In year-1, sulfur compounds tended to increase slightly through $5 \mathrm{~d}$ then decline through storage in FS and 3/4-slip cubes, whereas levels only increased for 2 $\mathrm{d}$ before declining in 1/2-slip and 1/4-slip cubes. In year-2, sulfur compounds in the two maturity groups were again similar, yet the trend was inconsistent through $14 \mathrm{~d}$ storage at $4{ }^{\circ} \mathrm{C}$ (data not shown).

Alcohols. Throughout the fresh-cut portion of this study (excluding OR), the relative percentage for the 7 alcohols analyzed did not change significantly, nor display a significant maturity-dependent trend. The relative percentage ranged between $0.70 \%$ and $1.16 \%$ for the four "slip" maturities, and was slightly higher upon processing $(1.43 \%)$ in OR.

Aldehydes. Upon preparing fresh-cuts in year-1 and year-2, roughly $0.8 \%$ to $4 \%$ and $2.6 \%$ to $7.7 \%$, respectively, of the compounds were aldehydes, across all maturities. Percent aldehydes followed a decreasing linear trend that was maturity-dependent whereby 1/4-slip >1/2-slip >3/4-slip > FS. The magnitude of the slope decreased with maturity (1/4-slip $=0.314$ to $\mathrm{OR}=0.049$ ), an indication that the effect of storage time decreased as the maturity increased. This was established by the slope estimates for 3/4-slip (0.075), FS (0.040), and OR (0.049), which were not statistically different from $0(P=0.053,0.322,0.269$, respectively). Mean percent aldehydes for 1/4-slip $(6.2 \%)$ vs. OR $(1.9 \%)$ on day 0 , and $1 / 2$-slip $(4.3 \%)$ vs. OR on day 0 were statistically different $(P=0.05)$. Yet, by day 12, the mean percent aldehydes for the five maturity levels were not statistically different $(P$ $=0.05) ; 1 / 4$-slip $=1.7 \%, 1 / 2$-slip $=0.9 \%, 3 / 4$-slip $=$ $1.1 \%, \mathrm{FS}=1.2 \%$, and $\mathrm{OR}=1.0 \%$.

Considering that most aldehydes are believed to impart "green" or "grassy" notes, this is significant concerning processing fruit harvested excessively immature (i.e., $\leq 1 / 4$-slip). Lipoxygenase (LOX) activity was reported in honeydew melon mesocarp tissue (Lester, 1998), but not in cantaloupe mesocarp (Lester, 1990). Although some C. melo mesocarp tissue has limited LOX activity, this is important since hydroperoxide lyase (HPL) activity has been demonstrated in melons (Tijet et al., 2001). Subsequently, a re-examination of LOX and HPL activities may be necessary to verify if undesirable or off-flavors occur in various out-of-season or imported melons that are harvested or processed more immature.

\section{A balance of volatiles in stored fresh-cuts}

Holistically, unique optimum flavor is produced by a fine balance of numerous volatile compounds, sugars and acids (DeRovira, 1996). The upset balance or shift in endogenous ester compounds could be partially responsible for the apparent lack of characteristic flavor in fresh-cut cantaloupe through long-term storage. During ripening, sugars are glycolytically broken down to carry out numerous catabolic processes. Toward the end of the glycolytic sequence, pyruvate is formed and this pivotal compound either enters the tricarboxylic acid cycle (TCA), or is required to produce alcohols that also condense with amino acids to form branched chain esters. An increase in volatile production after cutting may occur due to increased respiration 


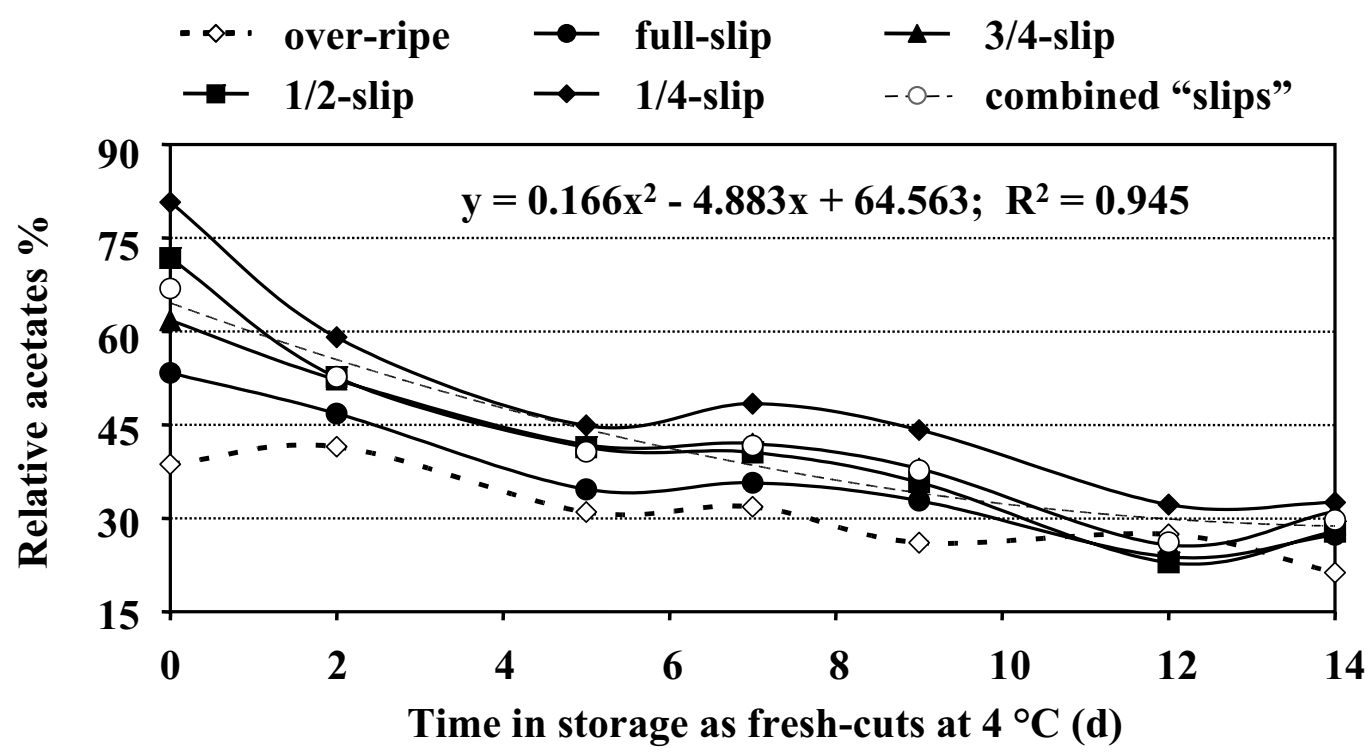

Fig. 6. Relative combined solid phase microextraction gas chromatograph-mass spectrometry percentage of 11 acetate esters $[\mathrm{CH}-\mathrm{C}(=\mathrm{O})-\mathrm{OR} \quad]$ recovered in stored $\left(4^{\circ} \mathrm{C}\right)$ fresh-cut cantaloupe prepared from five distinct maturities: 1/4-slip, 1/2-slip, 3/4-slip, full-slip (FS), and over-ripe (OR). Compounds used to generate classes are according to Table 1 . The linear equation was generated by combining 1/4-slip, 1/2-slip, 3/4-slip, and FS maturities, but not OR.

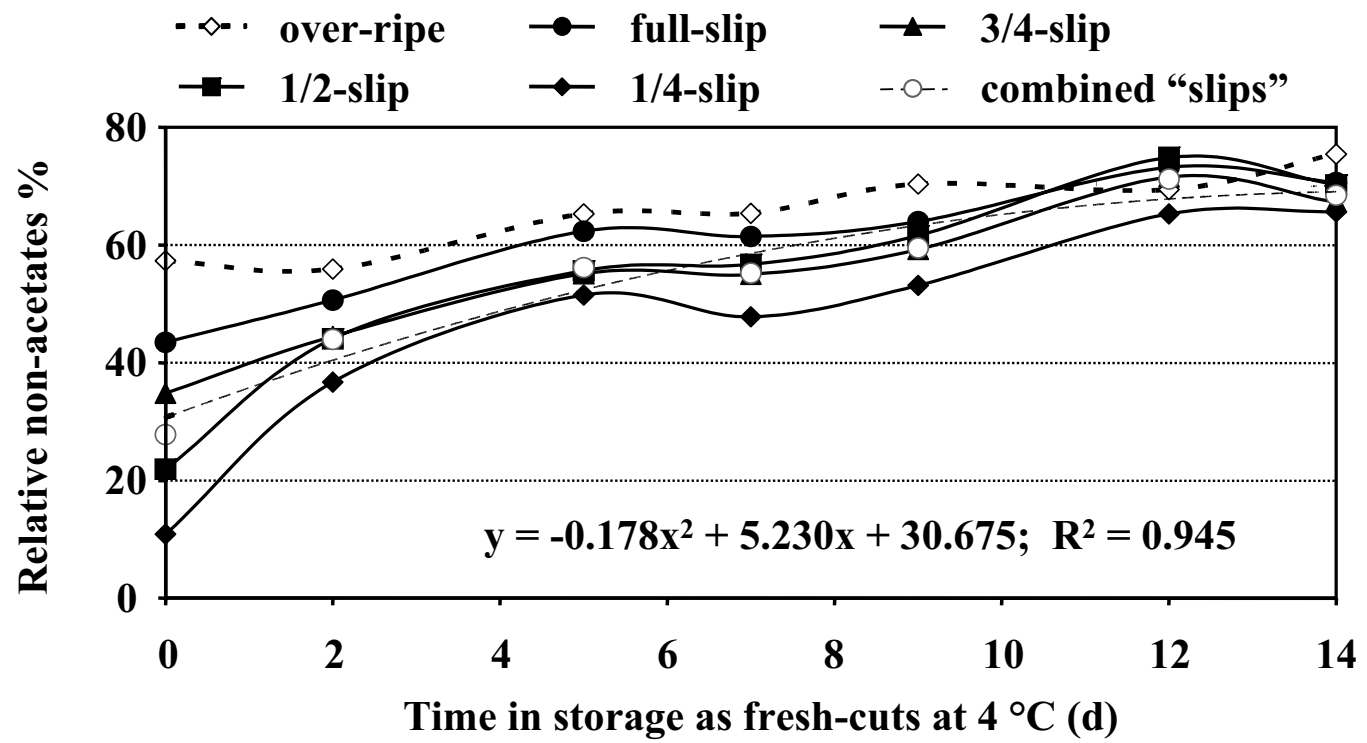

Fig. 7. Relative combined solid phase microextraction gas chromatograph-mass spectrometry percentage of 17 non-acetate esters $\left[\mathrm{R}_{\text {acid }} \mathrm{C}(=\mathrm{O})-\mathrm{OR} \quad\right]$ recovered in stored $\left(4^{\circ} \mathrm{C}\right)$ fresh-cut cantaloupe prepared from five distinct maturities: 1/4-slip, 1/2-slip, 3/4-slip, full-slip (FS), and over-ripe (OR). Compounds used to generate classes are according to Table 1 . The curvilinear equation was generated by combining 1/4-slip, 1/2-slip, 3/4-slip, and FS maturities, but not OR.

as more metabolic energy is driven through glycolysis and the TCA, releasing acetyl-CoA. The glycolytic and TCA pathways are also ultimately responsible for the production of the amino acids alanine, isoleucine, leucine, methionine and valine. The concentration of these amino acids increase with fruit ripening (Wyllie et al., 1995, 1996), and they are the putative precursors to numerous flavor esters and thioesters in muskmelons (Yabumoto et al., 1977), along with acetyl-CoA and various alcohols (Ueda et al., 1997; Yahyaoui et al., 2002).

Cutting tissue effectively increases the internal oxygen concentration. After hypoxic storage, the constituent biosynthetic rate of ester formation in apple discs increased as a result of air exposure (Rudell et al., 2002). Increased oxygen could also facilitate increased oxidative reactions (i.e., $\beta$-oxidation, $\beta$-carotene oxidation, and/or LOX-activity) that are required to deliver various straight chain fatty acid moieties, which condense with alcohols to form esters. Removal of the skin and decreased resistance to gaseous diffusion may allow for more rapid offgassing of volatiles from the tissue at the cut surface, which, is perceived as a transient ester increase. Nonetheless, important CIFAC acetates, requiring an amino acid backbone, decline during fresh-cut storage due to catabolism or a lack of substrate for synthesis. Since AAT is not limiting during later stages of fruit ripening (Fellman and Mattheis, 1995), the breakdown products appear to be re-circulated preferentially into nonacetate esters. Alternatively, esterases might favor breaking down acetate esters due to less steric interference about the ester bond upon which they act. Thus, an in-depth radiolabelled analysis of volatile precursors (alcohols, carboxylic acids, key lipids, and amino acids) and their associated enzymes such as LOX, pyruvate decarbox- 


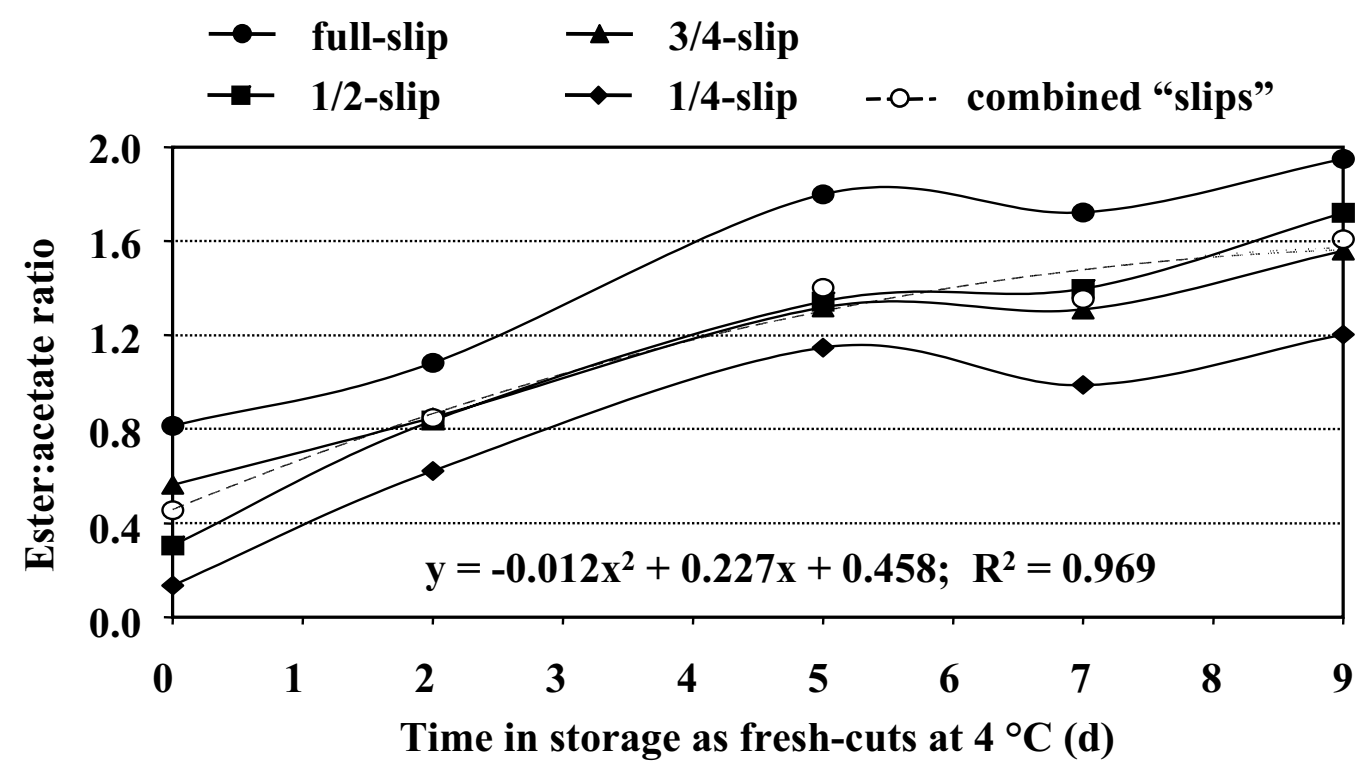

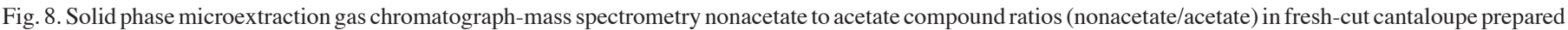

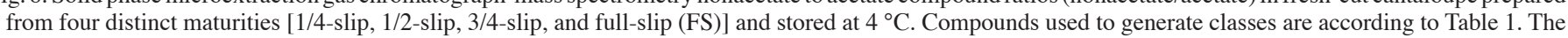
curvilinear equation was generated by combining all four maturities.

ylase, pyruvate dehydrogenase, alcohol dehydrogenase (ADH), acyl CoA reductase, AAT, and the amino acid-related enzymes $\alpha$-aminotransferase, $\alpha$-ketoacid decarboxylase, and $\alpha$-ketoacid dehydrogenase might explain the perceived re-cycling of esters during fresh-cut cantaloupe storage.

It has been determined that fruit specific and ethylene-regulated genes belong to a large acyl-transferase multifunctional gene family, specifically and increasingly expressed in early and mid phases of ripening, which were severely reduced in ethylene-suppressed antisense ACC oxidase fruit and in wild-type fruit treated with the ethylene antagonist 1-MCP (Yahyaoui et al., 2002). Dissimilar patterns of ethylene production have been reported in various fresh-cut melons (Luna-Guzmán et al., 1999; Saftner et al., 2003). Subsequently, a detailed evaluation of the ethylene burst upon cutting, subsequent duration and long-term capacity for ethylene production in stored fresh-cut climacteric fruit is also warranted.

\section{Conclusion}

Using this SPME GC-MS method and informal sensory appraisal, it was determined that aldehydes comprised the majority of recovered compounds during cantaloupe growth and development. With few exceptions (i.e., aldehydes), the recovery for most compound classes always increased with increasing harvest maturity, and 1/4-slip cubes contained only $5.6 \%$ to $30.5 \%$ recovery compared to FS cubes.

Based on integrated ion abundance after fresh cutting, a transient increase in many flavor-related esters and acetates occurred, often with substantial declines usually $7 \mathrm{~d}$ after processing. This trend varies slightly depending upon harvest maturity when fresh-cuts are stored at $4{ }^{\circ} \mathrm{C}$. The trend in volatiles is generally conserved for most compounds previously reported as imparting characteristic melon flavor. A transient increase in flavor compounds, often followed by sharp decreases in key volatiles and subsequent decrease in desirable sensory attributes (Beaulieu et al., 2004), is highly significant for fresh-cut fruit considering consumer satisfaction. The consumer often does not purchase a fresh-cut product until
2 to $5 \mathrm{~d}$ after processing, and temperature abuse will exacerbate probable flavor loss or change that may occur throughout the ensuing marketing and consumption windows. These maturitydependent volatile data indicate clearly that harvest maturity is important for optimizing fresh-cut flavor quality.

Upon processing (day 0), significant linear increases were found for most volatile classes that were maturity-dependent. On day 0 , most flavor-related acetates, aromatics, and S-compounds were at their maximum, provided the fruit was greater than 1/2-slip. In general, acetates, aldehydes, and aromatics seldom displayed a transient increase in abundance and relative percentage recovery during storage. After cutting, there was a gradual increase in overall recovery for nonacetate esters, especially when fruit were at least 1/2-slip at harvest (Fig. 5). Gradual increases in esters $\left[\mathrm{R}_{\text {acid }}-(\mathrm{C}=\mathrm{O})-\mathrm{OR}_{\text {organic }}\right]$ were generally accompanied by substantial (e.g., $27.0 \%$ to $82.8 \%$ in FS after 9 to $12 \mathrm{~d}$ storage) acetate $\left[\mathrm{CH}_{3}-\left(\mathrm{C}(=\mathrm{O})-\mathrm{OR}_{\text {organic }}\right]\right.$ declines. Further aroma volatile and sensory analyses are needed to characterize how and why certain volatile compounds in fresh-cut fruit appear to transiently increase, then decline through storage. A correlation between sensory attributes and volatile classes and individual volatiles is therefore warranted.

Assuming that roughly 19 non-S-containing compounds (especially acetates and aromatics) are critical to cantaloupe flavor, these combined data indicate that there are greater quantities of flavor-related compounds in more mature fruit, and these compounds decrease appreciably after $7 \mathrm{~d}$ storage. Furthermore, based on relative percentage of recovery, the data indicate that the balance of acetates vs. nonacetate esters changes significantly after just $2 \mathrm{~d}$ storage, and the shift in relative compound classes continues throughout fresh-cut storage. There is a consistent change in the ester balance through fresh-cut storage, which is independent of initial processing maturity.

\section{Literature Cited}

Ai, J. 1998. Solid-phase microextraction in headspace analysis. Dynamics in non-steady-state mass transfer. Anal. Chem. 70(22):4822-4826.

Bauchot A.D., D.S. Mottram, A.T. Dodson, and P.J. John. 1998. Effect 
of aminocyclopropane-1-carboxylic acid oxidase antisense gene on the formation of volatile esters in cantaloupe Charentais melon (cv. Vedrandais). J. Agr. Food Chem. 46(11):4787-4792.

Beaulieu, J.C. 2001. In search of better tasting fresh-cut fruit. Fresh Cut 9.4(April):14-16.

Beaulieu, J.C. 2006. Effect of cutting and storage on acetate and nonacetate esters in convenient, ready to eat fresh-cut melons and apples. HortScience (In press)

Beaulieu, J.C. and E.A. Baldwin. 2002. Flavor and aroma of fresh-cut fruits and vegetables, p. 391-425. In: O. Lamikanra (ed.). Fresh-cut fruits and vegetables. Science, technology and market. CRC Press, Boca Raton, Fla.

Beaulieu, J.C. and C.C. Grimm. 2001. Identification of volatile compounds in cantaloupe at various developmental stages using solid phase microextraction. J. Agr. Food Chem. 49(3):1345-1352.

Beaulieu, J.C., D.A. Ingram, J.M. Lea, and K.L. Bett-Garber. 2004. Effect of harvest maturity on the sensory characteristics of fresh-cut cantaloupe. J. Food Sci. 69(7):S250-S258.

Beaulieu, J.C. and J.M. Lea. 2003a. Aroma volatile differences in commercial orange-fleshed cantaloupes, the inbred parental lines, and stored fresh-cuts. Acta Hort. 628:809-815.

Beaulieu, J.C. and J.M. Lea. 2003b. Volatile and quality changes in fresh-cut mangos prepared from firm-ripe and soft-ripe fruit, stored in clamshell containers and passive MAP. Postharvest Biol. Technol. 30(1):15-28.

Bett, K.L., D.A. Ingram, C.C. Grimm, S.W. Lloyd, A.M. Spanier, J.M. Miller, K.C. Gross, E.A. Baldwin, and B.T. Vinyard. 2001. Flavor of fresh-cut 'Gala' apples in modified atmosphere packaging as affected by storage time. J. Food Qual. 24(2):141-156.

Bett-Garber, K.L., J.C. Beaulieu, and D.A. Ingram. 2003. Effect of storage on sensory properties of fresh-cut cantaloupe varieties. J. Food Qual. 26:323-335.

Bezman, Y., F. Mayer, G.R. Takeoka, R.G. Buttery, G. Ben-Oliel, H.D. Rabinowitch, and M. Naim. 2003. Differential effects of tomato (Lycopersicon esculentum Mill) matrix on the volatility of important aroma compounds. J. Agr. Food Chem. 51(3):722-726.

Binder, R.G., R.A. Flath, and T.R. Mon. 1989. Volatile components of bittermelon. J. Agr. Food Chem. 37:418-420.

Buttery, R.G., R.M. Seifert, L.C. Ling, E.L. Soderstrom, J.M. Ogawa, and J.G. Turnbaugh. 1982. Additional aroma components of honeydew melon. J. Agr. Food Chem. 30(6):1208-1211.

DeRovira, D. 1996. The dynamic flavor profile method. Food Technol. 50(2):55-60.

Evensen, K.B. 1983. Effects of maturity at harvest, storage temperature, and cultivar on muskmelon quality. HortScience 18:907-908.

Fallik, E., S. Alkali-Tuvia, B. Horev, A. Copel, V. Rodov, Y. Aharoni, D. Ulrich, and H. Schulz. 2001. Characterisation of 'Galia' melon aroma by GC and mass spectrometric sensor measurements after prolonged storage. Postharvest Biol. Technol. 22(1):85-91.

Fellman, J.F., T.W. Miller, D.S. Mattison, and J.P. Mattheis. 2000. Factors that influence biosynthesis of volatile flavor compounds in apple fruit. HortScience 35:1026-1033.

Fellman, J.K. and J.P. Mattheis. 1995. Ester biosynthesis in relation to harvest maturity and controlled-atmosphere storage of apples, p. 149-162. In: R.L Rouseff and M.M. Leahy (eds.). Fruit flavors: Biogenesis, characterization, and authentication. Amer. Chem. Soc., Washington, D.C.

Fleming, H.P., W.Y. Cobb, J.L. Etchells, and T.A. Bell. 1968. The formation of carbonyl compounds in cucumbers. J. Food Sci. 33:572-576.

Gardner, H.W. 1989. How the lipoxygenase pathway affects the organoleptic properties of fresh fruit and vegetables, p. 98-112. In: D.B. Min and T.H. Smouse (eds.). Flavor chemistry of lipid foods. The Amer. Oil Chem. Soc., Champaign, Ill.

Gross, G.G. 1981. Phenolic acids, p. 301-315. In: E.E. Conn (ed.), The biochemistry of plants, vol. 7. Academic, New York.

Hansson, A., J. Andersson, and A. Leufven. 2001a. The effect of sugars and pectin on flavour release from a soft drink-related model system. Food Chem. 72(3):363-368.
Hansson, A., J. Andersson, A. Leufven, and K. Pehrson. 2001b. Effect of changes in $\mathrm{pH}$ on the release of flavour compounds from a soft drink-related model system. Food Chem. 74(4):429-435.

Harada, M., Y. Ueda, and T. Iwata. 1985. Purification and some properties of alcohol acetyltransferase from banana fruit. Plant Cell Physiol. 26:1067-1074.

Horvat, R.J. and S.D. Senter. 1987. Identification of additional volatile compounds from cantaloupe. J. Food Sci. 52(4):1097-1098.

Ibáñez, E., S. López-Sebastián, E.U. Ramos, J. Tabera, and G. Reglero. 1998. Analysis of volatile fruit components by headspace solid-phase microextraction. Food Chem. 63(2):281-286.

Jia, M.Y., Q.H. Zhang, and D.B. Min. 1998. Optimization of solid-phase microextraction analysis for headspace flavor compounds of orange juice. J. Agr. Food Chem. 46(7):2744-2747.

Kemp, T.R., L.P. Stoltz, and D.E. Knavel. 1972. Volatile components of muskmelon fruit. J. Agr. Food Chem. 20(2):196-198.

Lamikanra, O., B. Juaraez, M.A. Watson, and O.A. Richard. 2003. Effect of cutting and storage on sensory traits of cantaloupe melon cultivars with extended postharvest shelf life. J Sci. Food Agr. 83:702-708.

Lamikanra, O. and O.A. Richard. 2002. Effect of storage on some volatile aroma compounds in fresh-cut cantaloupe melon. J. Agr. Food Chem. 50(14):4043-4047.

Lamikanra, O. and O.A. Richard. 2004. Storage and ultraviolet-induced tissue stress effects on fresh-cut pineapple. J. Sci. Food Agr. 84:1812-1816.

Lester, G.E. 1990. Lipoxygenase activity of hypodermal and middle mesocarp tissue from netted muskmelon fruit during maturation and storage. J. Amer. Soc. Hort. Sci. 115:612-615.

Lester, G.E. 1998. Physicochemical characterization of hybrid honey dew muskmelon fruit (Cucumis melo L. var. inodorus Naud.) following maturation, abscission and postharvest storage. J. Amer. Soc. Hort. Sci. 123:126-129.

Luna-Guzmán, I., M.I. Cantwell, and D.M. Barrett. 1999. Fresh-cut cantaloupe: Effects of $\mathrm{CaCl}_{2}$ dips and heat treatments on firmness and metabolic activity. Postharvest Biol. Technol. 17:201-213.

McLafferty, F. 2000. Wiley registry of mass spectral data, 7th ed. Wiley 7th/NIST02 software, May 2000, Palisade Corp., Newfield, N.Y. 1 Nov. 2004; <http://www.wiley.com/WileyCDA/WileyTitle/productCd0471440973.html>

Meilgaard, M., G.V. Civille, and B.T. Carr. 1999. Sensory evaluation techniques. 3rd ed. CRC Press, Boca Raton, Fla.

Murray, R.A. 2001. Limitations to the use of solid-phase microextraction for quantitation of mixtures of volatile organic sulfur compounds. Anal. Chem. 73(7):1646-1649.

Niedziella, S., S. Rudkin, and M. Cooke. 2000. Evidence for selectivity of absorption of volatile organic compounds by a polydimethylsiloxane solid-phase microextraction fibre. J. Chromatography A. 885(1-2):457-464

Nijssen, L.M., C.A. Visscher, H. Maarse, L.C. Willemsens, and M.H. Boelens. 1996. Melons (10), p. 10.1-10.8. In: L.M. Nijssen, C.A. Visscher, H. Maarse, L.C. Willemsens, and M.H. Boelens (eds.). Volatile compounds in food-Qualitative and quantitative data. 7th $^{\text {ed. TNO }}$ Nutr. and Food Research Inst., Zeist, The Netherlands.

Nussbaumer, C. and B. Hostettler. 1996. New flavour compounds of Cucumis melo L, p. 70-73. In: A.J. Taylor and D.S. Mottram (eds.). Flavour science: Recent developments. Royal Soc. Chem., Cambridge, U.K.

Ogle, W.L. and E.P. Christopher. 1957. The influence of maturity, temperature, and duration of storage on quality of cantaloupes. Proc. Amer. Soc. Hort. Sci. 70:319-324.

Pérez, A.G., L.C. Sanz, R. Olías, J.J. Rios, and J.M. Olías. 1996. Evolution of strawberry alcohol acyltransferase activity during fruit development and storage. J. Agr. Food Chem. 44(10):3286-3290.

Pratt, H.K. 1971. Melons, p. 207-232. In: A.C. Hulme (ed.). The biochemistry of fruits and their products. Academic, New York.

Rocha, S., V. Ramalheira, A. Barros, I. Delgadillo, and M.A. Coimbra. 2001. Headspace solid phase microextraction (SPME) analysis of 
flavor compounds in wines. Effect of the matrix volatile composition in the relative response factors in a wine model. J. Agr. Food Chem. 49(11):5142-5151.

Rudell, D.R., D.S. Mattinson, J.P. Mattheis, S.G. Wyllie, and J.K. Fellman. 2002. Investigations of aroma volatile biosynthesis under anoxic conditions and in different tissues of "Redchief Delicious" apple fruit (Malus domestica Borkh.). J. Agr. Food Chem. 50(9):2627-2632.

Saftner, R.A., J. Bai, J.A. Abbott, and Y.S. Lee. 2003. Sanitary dips with calcium propionate, calcium chloride, or a calcium amino acid chelate maintain quality and shelf stability of fresh-cut honeydew chunks. Postharvest Biol. Technol. 29:257-269.

Schieberle, P., S. Ofner, and W. Grosch. 1990. Evaluation of potent odorants in cucumbers (Cucumis sativus) and muskmelons (Cucumis melo) by aroma extract dilution analysis. J. Food Sci. 55(1):193-195.

Shalit, M., N. Katzir, Y. Tadmor, O. Larkov, Y. Burger, F. Shalekhet, E. Lastochkin, U. Ravid, O. Amar, M. Edelstein, Z. Karchi, and E. Lewinsohn. 2001. Acetyl-CoA: Alcohol acetyltransferase activity and aroma formation in ripening melon fruits. J. Agr. Food Chem. 49(2):794-799.

Shiota, H. 1990. Changes in the volatile composition of La France pear during maturation. J. Sci. Food Agr. 52(3):421-429.

Spanier, A.M., M. Flores, C. James, J. Lasater, S. Lloyd, and J.A. Miller. 1998. Fresh-cut pineapple (Ananas sp.) flavor. Effect of storage, p. 331-343. In: E.T. Contis, C.T. Ho, C.J. Mussinan, T.H. Parliment, F. Shahidi, and A.M. Spanier (eds.). Developments in food science. Food flavors: Formation, analysis, and packaging influences. Elsevier Science Publ., Amsterdam.

Tijet, N., C. Schneider, B.L. Muller, and A.R. Brash. 2001. Biogenesis of volatile aldehydes from fatty acid hydroperoxides: Molecular cloning of a hydroperoxide lyase (CYP74C) with specificity for both the 9and 13-hydroperoxides of linoleic and linolenic acids. Arch. Biochem. Biophys. 386(2):281-289.

Toivonen, P.M.A. and J.R. DeEll. 2002. Physiology of fresh-cut fruits and vegetables, p. 91-123. In: O. Lamikanra (ed.). Fresh-cut fruits and vegetables. Science, technology and market. CRC Press, Boca Raton, Fla.

Ueda, Y., N. Fujishita, and K. Hachin. 1997. Presence of alcohol acetyltransferase in melons (Cucumis melo L.). Postharvest Biol. Technol. 10(2):121-126.
Watada, A.E. and L. Qi. 1999. Quality of fresh-cut produce. Postharvest Biol. Technol. 15(3):201-205.

Wiley, R.C. 1994. Minimally processed refrigerated fruits \& vegetables. Chapman \& Hall, London.

Wyllie, S.G. and D.N. Leach. 1990. Aroma volatiles of Cucumis melo cv. Golden Crispy. J. Agr. Food Chem. 38(11):2042-2044.

Wyllie, S.G. and D.N. Leach. 1992. Sulfur-containing compounds in the aroma volatiles of melons (Cucumis melo). J. Agr. Food Chem. 40(2):253-256.

Wyllie, S.G., D.N. Leach, and Y. Wang. 1996. Development of flavor attributes in the fruit of $C$. melo during ripening and storage, p. 228-239. In: G.R. Takeoka, R. Teranishi, P.J. Williams, and A. Kobayashi (eds.). Biotechnology for improved foods and flavors. Amer. Chem. Soc., Washington, D.C.

Wyllie, S.G., D.N. Leach, Y. Wang, and R.L. Shewfelt. 1994. Sulfur volatiles in Cucumis melo cv. Makdimon (muskmelon) aroma. Sensory evaluation by gas chromatography-olfactometry. Amer. Chem. Soc. Symp. Ser. 564:36-48.

Wyllie, S.G., D.N. Leach, Y. Wang, and R.L. Shewfelt. 1995. Key aroma compounds in melons: Their development and cultivar dependence, p. 248-257. In: R.L. Rouseff and M.M. Leahy (eds.). Fruit flavors: Biogenesis, characterization, and authentication. Amer. Chem. Soc., Washington, D.C.

Yabumoto, K., M. Yamaguchi, and W.G. Jennings. 1977. Biosynthesis of some volatile constituents of muskmelon, Cucumis melo. Chemie Mikrobiologie Technologie Lebensmittel 5:53-56.

Yabumoto, K., M. Yamaguchi, and W.G. Jennings. 1978. Production of volatile compounds by muskmelon, Cucumis melo. Food Chem. $3(1): 7-16$.

Yahyaoui, F.E.L., C. Wongs-Aree, A. Latché, R. Hackett, D. Grierson, and J.C. Pech. 2002. Molecular and biochemical characteristics of a gene encoding an alcohol acyl-transferase involved in the generation of aroma volatile esters during melon ripening. European J. Biochem. 269(9):2359-2366.

Yajima, I., H. Sakakibara, J. Ide, T. Yanai, and K. Hayashi. 1985. Volatile flavor components of watermelon (Citrullus vulgaris). Agr. Biol. Chem. (Tokyo). 49(11):3145-3150.

Yang, S.F. and N.E. Hoffman. 1984. Ethylene biosynthesis and its regulation in higher plants. Ann. Rev. Plant Physiol. 35:135-189. 